\title{
Geschlechtswechsel unter der NS-Herrschaft "Transvestitismus", Namensänderung und Personenstandskorrektur in der "Ostmark“ am Beispiel der Fälle Mathilde/Mathias Robert S. und Emma/Emil Rudolf K.
}

The phenomenon of juridical sex change during the National Socialist era in Austria is hitherto unresearched. After outlining the current state of research and detailing the legal frameworks, this paper will present, for the first time, two cases of juridical female-to-male sex change that took place after the "Anschluss" in 1938. Classified at the time under "transvestitism", in modern terminology the cases covered here concern women who cross-dressed/passed and intersex or transgender people. The paper will deal with questions of police acceptance of the wearing of the clothes of the opposite sex, first name changes, and changes to marital status.

\section{Einleitung}

Das von der Forschung bislang wenig beachtete Phänomen des Geschlechtswechsels in der Zeit des Nationalsozialismus wird im Folgenden nicht nur auf der Grundlage des aktuellen Forschungsstandes dargestellt, sondern es werden erstmals auch Fälle aus der "Ostmark" präsentiert. Zeitgenössisch wurden diese beiden Fälle einer juristischen Frau-zu-Mann-Geschlechtsumwandlung unter dem Begriff „Transvestitismus" erfasst, in der heutigen Terminologie wäre wohl von Crossdresserinnen, Passing women bzw. Tansgender- oder Intersex-Personen zu sprechen

\subsection{Begriffliches}

Der Begriff des „Transvestitismus“ wurde erstmals 1910 vom Sexualwissenschaftler Magnus Hirschfeld eingeführt und bezeichnet einen "heftigen Drang“, „in der Kleidung desjenigen Geschlechts zu leben, dem die Betreffenden ihrem Körperbau nach nicht angehören“.. ${ }^{1}$ Der Transvestit wird Hirschfeld zufolge „von Geburt an aus innerer Veranlagung von dem Drang beherrscht $[\ldots]$, sein Leben nach jeder Richtung hin den Gewohnheiten des anderen Geschlechtes entsprechend zu führen“, und da "die männliche oder weibliche Lebensführung im Wesentlichen durch die verschiedenartige Kleidung ausgedrückt ist, zeigt sich die Veranlagung darin, daß ihre Träger von einem unwiderstehlichen Zwange beherrscht sind, sich nach der Art des anderen Geschlechts zu kleiden“. Die „Erfüllung des Triebes“ bewirke „eine so erschöpfende Befriedigung und völlige Entspannung der Sexualität, daß alle anderen geschlechtlichen Regungen sich ihr unterordnen und ihr gegenüber mehr oder weniger zurücktreten". ${ }^{2}$ Transvestitismus als seelisches Bedürfnis des Veroder besser „Umkleidens" hat also seinen „Ur-

\footnotetext{
${ }^{1}$ HIRSCHFELD Transvestiten 159.

${ }^{2}$ HiRSCHFELD, Schuldig geboren 16.
} 
sprung nicht in biologischen, sondern in psychischen Faktoren". ${ }^{3}$

Wenngleich der Begriff „Transvestit“ in der heutigen Alltagssprache nur Männer erfasst, fand er historisch ebenso auf Frauen Anwendung. So stellt (auch) der "weibliche Transvestitismus" eine "sexualwissenschaftliche Erfindung der Jahrhundertwende" dar, ${ }^{4}$ obwohl Hirschfeld selbst den „Transvestiten“-Begriff ebenfalls primär auf Männer anwendete, da nur „ganz wenige Frauen [...] das Transvestieren als Mittel zur sexuellen Erregung benutzen". 5

Der Begriff „Cross-Dressing“ wurde von heterosexuellen Cross-DresserInnen in den 1970erJahren in Abgrenzung zum Begriff des „Transvestitismus" geschaffen, der aufgrund der damit verbundenen Pathologisierung und negativen Konnotationen vielfach auf Ablehnung stieß, ${ }^{6}$ und bezeichnet jedwedes Tragen andersgeschlechtlicher Kleidung. Auch wird seit dieser Zeit der Begriff des "Passing" im Sinne eines "Cross-Living" verwendet, weil sowohl "Transvestitismus" als auch "Cross-Dressing" als allein auf die Kleidung verkürzende Bezeichnungen erscheint. ${ }^{7}$

Hirschfeld ordnete die „Transvestiten" den verschiedenen „sexuellen Zwischenstufen“ zu, die er innerhalb der Pole „Vollmann" und „Voll-

\footnotetext{
${ }^{3}$ DEKKER, POL, Frauen 73.

${ }^{4}$ HACKER Ordnung 191.

${ }^{5}$ KAPLAN, Perversionen 34; vgl. MAK, Passing Women; MAK, Hirschfeld.

${ }^{6}$ STRYKER, Transgender History, 17f; EKINS, KING, The transgender phenomenon 30.

${ }^{7}$ Nach KATZ, Passing Women 320, ist daher das "cross-dressing" um "cross-working" und "cross-speaking" zu erweitern: "While the adoption of the costume of the ,opposite' sex is certainly important [...], their adoption of the occupation, vocabulary, tone of voice, gesture, walk, sports and aspirations of the, other' sex are equally significant. To appreciate the full complexity of these lives, the conception of transvestism or cross-dressing needs to be supplemented by such concepts as cross-working an crossspeaking", zit. n. HACKER, Ordnung 67-70; vgl. auch RuNTE, Operationen 340.
}

weib" anhand der Parameter Geschlechtsorgane, sonstige körperliche Eigenschaften, Geschlechtstrieb und weitere seelische Eigenschaften definierte, wobei ihm Transvestitismus als eine Zwischenstufe "sonstiger seelischer Eigenschaften" galt. "Sexuelle Zwischenstufen" waren nach Hirschfeld gleichfalls u.a. Bi- und Homosexuelle, bestimmt durch den Geschlechtstrieb, androgyne Frauen, also Frauen mit „überwiegend männlichen Charaktereigenschaften und Trieben", und "Hermaphroditen" oder "Zwitter", wobei er je nach konkreter körperlicher Beschaffenheit neben echtem "Hermaphroditismus" auch männliches und weibliches „Scheinzwittertum" (Pseudohermaphroditismus) mit jeweils überwiegend männlichen oder weiblichem Habitus herausdifferenzierte. ${ }^{8}$ Den modernen Begriff der Intersexualität, also der Unmöglichkeit, einen Menschen genetisch und/oder anatomisch und hormonell eindeutig dem weiblichen oder dem männlichen Geschlecht zuzuordnen, prägte erst 1917 der Genetiker Richard Goldschmidt. ${ }^{9}$

Für diejenigen Transvestiten, die über das Tragen der Kleidung des Gegengeschlechts hinaus (auch körperlich) einen Wechsel zum „,anderen“ Geschlecht vollziehen wollten, verwendete erstmals Hirschfeld 1923 den Begriff „Transsexualismus". 1949 griff David O. Cauldwell ${ }^{10}$ diesen Begriff auf, und Harry Benjamin ${ }^{11}$ machte ihn in den 1950er- und 1960er-Jahren einer breiteren Öffentlichkeit bekannt. Wenngleich Benjamin den „Transvestitismus" noch als schwächstes Phänomen der Transsexualität erachtete, wurde in weiterer Folge Transsexualität als Geschlechtsidentitätsproblem bzw. Wunsch, als Angehörige/r des "anderen“ anatomischen Geschlechts zu leben und anerkannt zu werden, grundsätzlich vom „Transvestitismus" im Sinne

\footnotetext{
${ }^{8}$ Vgl. ausf HIRSCHFELD, Geschlechtsübergänge; vgl. auch FAUSTO-STERLING, Sexing the Body 38.

${ }^{9}$ Domurat Dreger, Hermaphrodites 31.

${ }^{10}$ CAuldwell, Psychopathia Transsexualis.

${ }^{11}$ Siehe z.B. Benjamin, Transvestitism.
} 
einer sexuellen Neigung unterschieden. Transsexuelle bewegt also "alles andere als Lust“, da sie unter einer "Spaltung zwischen Körper und Seele" leiden. ${ }^{12}$

Der Begriff „Transgender", erstmals vermutlich von Virginia Price 1969 im Magazin „Transvestia" verwendet, 13 wurde dann seit den 1980erJahren nicht nur für Menschen verwendet, welche die soziale Geschlechtsrolle vollständig wechselten (unabhängig von geschlechtsangleichenden Maßnahmen), sondern als genderpolitischer Oberbegriff für diejenigen Personen, die sich sichtbar der klassischen Zuordnung einer Geschlechtsrolle entziehen, wie dies eben z.B. bei Transsexuellen der Fall ist. Daher gleicht die Verwendung des Begriffes Transgender nunmehr dem des "Transvestitismus“ in dessen Anfangszeit. ${ }^{14}$

Wenngleich vielfach damit verbunden, ist "Transvestitismus" keineswegs mit Homosexualität gleichzusetzen, wiewohl dieser Hirschfeld zufolge sowohl mit Androgynie als auch mit Homosexualität „,vergesellschaftet" sein könne. ${ }^{15}$ Im Unterschied zu Richard Krafft-Ebing, der im Verkleidungstrieb nur eine Art der „conträren Sexualempfindung" bzw. Homosexualität erblickte, ${ }^{16}$ betonte Hirschfeld, ${ }^{17}$ dass der (männliche) Transvestitismus zwar als eine den Homosexuellen typischer Weise zukommende Eigenschaft bezeichnet werden könne, die Mehrzahl der Transvestiten jedoch nicht homosexuell sei. ${ }^{18}$ Wie der Mediziner Hans Abraham 1912 hervorhob, würde dieser Befund „noch deutlicher" zu

\footnotetext{
12 WACKE, Hermaphroditen 893.

${ }^{13}$ EKINS, KING, The transgender phenomenon 13.

14 STRYKER, Transgender History 17.

${ }^{15}$ HirsChFELD, Sexualpathologie 156.

${ }^{16}$ KRAfFT-EbBING, Psychopathia Sexualis 209ff, insbes. $280 \mathrm{f}$.

${ }^{17}$ HeRrN, Schnittmuster 63; vgl. zu den Gründen MAK, Passing Women 17.

${ }^{18}$ Von den 16 in seinem Buch „Transvestiten“ veröffentlichten Fällen waren nur 35\% homo- und 15\% bisexuell, vgl. ABRAHAM, Transvestitismus 3.
}

Tage treten, „wenn wir die männlichen Transvestiten allein betrachten“, da "unter den weiblichen Transvestiten die Heterosexuellen die verschwindende Ausnahme“ darstellten. ${ }^{19}$ "Transvestitismus" war für Hirschfeld jedenfalls nicht mit Homosexualität ident und sollte als solcher auch nicht zu einer homosexuellen Verdächtigung führen dürfen,,$^{20}$ was angesichts der Strafbarkeit von Homosexualität (für Männer in Deutschen Reich und beide Geschlechter in Österreich) auch durchaus von hoher Praxisrelevanz war. Zahlreiche andere Autoren gingen im 19. und frühen 20. Jahrhundert jedoch in Fällen des Transvestitismus von einer zumindest latenten bzw. passiven Homosexualität aus, ${ }^{21}$ was wie aus Selbstzeugnissen - hervorgeht, jedenfalls bei den heterosexuellen männlichen CrossDressern aufgrund der pejorativen Besetzung der Homosexualität durchaus auf Widerstand stieß.22 "Cross-Dressing" wurde folglich, so Rainer Herrn, in dieser Zeit "nicht als singuläre Erscheinung verstanden", sondern vielmehr als „sichtbare[r] und damit essenzielle[r] Bestandteil der als fortschreitender Prozess der Geschlechterdegeneration gedeuteten conträren Geschlechtsempfindung“, womit auch die „Kleidung ein Symptom zu deren Diagnose“ darstellte. ${ }^{23}$

Betreffend die "conträre Geschlechtsempfindung" von Frauen hatte schon der englische Sexualforscher Henry Havelock Ellis Ende des 19. Jahrhunderts generell einen Zusammenhang zwischen „Männlichkeit" von Frauen und lesbischer Identität gesehen, ${ }^{24}$ ebenso Krafft-Ebing, der als "schwerste Stufe degenerativer Homosexualität" die Gynandrie bezeichnete, bei der es

\footnotetext{
${ }^{19}$ Ebd.

${ }^{20}$ HIRSCHFELD, Transvestiten $187 \mathrm{ff}$.

${ }^{21}$ Vgl. DIENES Transvestitismus 59; HERRN, Schnittmuster $75 \mathrm{ff}$.

${ }^{22}$ Vgl. HERRN, Schnittmuster 31, 37.

${ }^{23}$ Ebd. 30.

${ }^{24}$ Vgl. MAK, Passing Women 398.
} 
sich „um Weiber" handle, „die vom Weib nur die Genitalorgane haben, im Fühlen, Denken, Handeln und in der äusseren Erscheinung aber durchaus männlich erscheinen" ${ }^{25}$

Als ein, sich mit der sexuellen Orientierung und auch dem "Transvestitismus" teilweise überschneidendes Phänomen wurde außerdem der Kampf der Feministinnen des 19. und frühen 20. Jahrhunderts gegen die Unterdrückung durch Kleidung(svorschriften) gesehen, der über die Reformkleidungsbewegung hinaus im Tragen von Männerkleidern - und damit auch polizeilichen Amtshandlungen, wie Verhaftungen oder polizeilichen Verboten des Hosentragens für Frauen - gipfelte. ${ }^{26}$ Hirschfeld ordnete die Frauenrechtlerinnen aber nicht als „Transvestitinnen“, sondern als „urnische“ Frauen ein, da gerade die "homosexuellen Frauen Eigenschaften (besitzen), die sie zu besonders aktiven Vorkämpferinnen für die Rechte der Frau befähigen". ${ }^{27}$ Havelock Ellis wiederum hatte der Frauenbewegung vorgeworfen, dass sie eine "Zunahme der Inversion" (Homosexualität) bewirke. ${ }^{28}$ Nach Iwan Bloch waren jedenfalls die Frauenrechtlerinnen nicht alle „lesbische Mannweiber", sondern vielmehr zumeist nur "Pseudolesbierinnen" bzw. von den "Mannweibern" verführte Frauen, ${ }^{29}$ wenngleich die Frauenbewegung die lesbische Orientierung fördere, weil sie einen „gefährlichen Überdruss am Manne" produziere. ${ }^{30}$ Der Sexualwissenschafter Albert Moll hingegen zweifelte den Zusammenhang von Frauenbewegung und sexueller Orientierung

\footnotetext{
${ }^{25}$ KRAFFT-EBING, Psychopathia Sexualis (1901) 281.

${ }^{26}$ HACKER, Ordnung, 205ff; HERRN, Schnittmuster 62.

${ }^{27}$ HiRSCHFELD, Uranismus 124, zit. n. SCHMERSAHL, Medizin 335-344.

${ }^{28}$ HAVELOCK ElLis, EdDington SymONDS, Konträres Geschlechtsgefühl, zit. n. SCHMERSAHL, Medizin 336; vgl. ausf. MAK, Passing Women 397f.

${ }^{29} \mathrm{BLOCH}$, Sexualleben, zit. n. SCHMERSAHL, Medizin 336.

${ }^{30} \mathrm{BLOCH}$, Ätiologie der Psychopathia sexualis 248f, zit. nach MeHLMANN, Körper 202.
}

überhaupt an und wies darauf hin, dass es unter den Frauenrechtlerinnen ,[g]ewiss [...] Homosexuelle“ gäbe, man fände aber ",auch eine ganze Reihe Heterosexueller unter ihnen, und zwar auch unter denen, die äußerlich schon nicht nur Neigung zu männlichen Berufen haben, sondern auch äußerlich männliche Bewegungen, männliche Körperformen zeigen." 31 Für den NS-Juristen Rudolf Klare hingegen war es eine „unleugbare Tatsache, daß zwischen der Frauenbewegung und der Ausdehnung lesbischen Verkehrs ein inniger Zusammenhang besteht". ${ }^{32}$

In der modernen Literatur ${ }^{33}$ wird freilich die Gleichsetzung von Cross-Dressing oder Passing und sexueller Orientierung grundsätzlich abgelehnt, sondern vielmehr betont, dass das „subversive Moment , anderer' Kleidung und , anderen' Gebarens und der Codewert, der in der äußeren Aufmachung liegt, von dem Etikett ,Lesbianismus' zu trennen" sei. ${ }^{34}$

\subsection{Forschungsstand}

Dem weiblichen "Transvestitismus", insbesondere im 19. und 20. Jahrhundert, wurde von der Geschichtswissenschaft, wie bereits Dekker und van den Pol feststellten, „überraschend wenig Beachtung geschenkt",35 was insbesondere für

\footnotetext{
${ }^{31}$ MoLL, Handbuch der Sexualwissenschaften 27, zit. n. SCHMERSAHL, Medizin 338.

32 KLARE, Problem 20.

33 So betont etwa ScHWARZ, Researching Lesbian History 59, dass "the mere fact, that a woman wore trousers or ties in an era of extreme feminine fashion does not make her a bona fide lesbian - she may simply have been doing the sensible thing any right-thinking independent woman would have done. "Passing women' who lived as men were fighting other grievances of women - they may or may not have also been lesbians", zit. n. HACKER, Ordnung 195.

${ }^{34}$ HACKER, Ordnung 195.

35 DEKKER, POL, Frauen 69; siehe für den außerdeutschen Raum etwa MAK, Menneljke vrouwen; weiters auch STEINBERG, La confusion des sexes; z.T. mit dem frühen 19. Jahrhundert: BARD, PELLEGRIN, Femmes travesties; GARBER, Vested interests; BULlOGH, BuL-
} 
die Rechtsgeschichte dieses Phänomens im deutschsprachigen Raum gilt. ${ }^{36}$ Dies ist umso erstaunlicher, als die Theorie für den weiblichen Transvestitismus verschiedene Erklärungen und damit Forschungsansätze anbietet: „biologische Intersektionalität, Transvestitismus, Homosexualität und Transsexualität."37 Die konkrete Zuordnung historischer Fälle zu diesen Erklärungsansätzen ist freilich schwierig, zumal das Tragen von Kleidern des Gegengeschlechts vielfach in der zeitgenössischen Praxis bloß als Symptom bzw. Hinweis auf Homosexualität gewertet wurde. Diese Überschneidung mit dem Homosexualitätsvorwurf erschwert dementsprechend die historische Forschung betreffend das Phänomen des Transvestitismus, da so die möglichen Quellenbestände schwer lokalisierbar sind, wie auch Herrn jüngst betonte. ${ }^{38}$ Daher liegen zur Geschichte des Transvestitismus kaum aktuelle Studien vor, die sich mit diesem Phänomen eigenständig, und nicht nur als reinem Unterfall von Homosexualität oder zum Teil auch Intersexualität beschäftigen. ${ }^{39}$ Eine Ausnahme stellen die Arbeiten Herrns dar, der für die Zeit des Nationalsozialismus allerdings konstatiert, dass die „Informationen über den Umgang mit Transvestitinnen [...] deutlich spärli-

LOUGH, Crossdressing; FeINBERG, Gender Warriors; LUCAS, Hic Mulier.

${ }^{36}$ Siehe die grundlegende Studie von WACKE, Hermaphroditen; für das Mittelalter und die frühe Neuzeit hingegen liegen historische (Detail-)Studien vor, z.B. STEIDELE, In Männerkleidern; LOSERT, Kleider; HAustein, Transvestitismus; STOLL, WODTKE-WeRnER, Sakkorausch; siehe auch die Literatur zu travestierenden Frauen im militärischen Zusammenhang: z.B. NoÉ, Amazonen.

${ }^{37}$ DEKKER, POL, Frauen 69.

${ }^{38}$ Vortrag Rainer Herrn am Workshop des Instituts für Zeitgeschichte München-Berlin im Februar 2013: „Ich habe wohl Freude an Frauenkleidern, bin aber deswegen nicht homosexuell“", vgl. WOLTER, Lebenssituationen.

39 Siehe etwa rezent KLÖPPEL, XXOXY ungelöst; SPÖRRI, N. O. Body 244-261; Domurat Dreger, Hermaphrodites. cher als jene über Transvestiten" sind und sich nur in Archivquellen finden, deren Auswertung nahelege, „dass mit Frauen, die Männerkleidung trugen, höchst unterschiedlich verfahren wur$\mathrm{de}^{\prime \prime} .40$

In der österreichischen historischen Literatur werden TransvestitInnen, wenn überhaupt, ausschließlich in homosexuellen Kontexten thematisiert, wie von Hanna Hacker, ${ }^{41}$ die für den von ihr behandelten Zeitraum von 1870 bis 1938 mehrere Fälle eines Passing von Arbeiterinnen aufweist, und von Niko Wahl, ${ }^{42}$ der sich mit Fällen männlichen Transvestitismus im Nationalsozialismus auseinandersetzt. Das hat freilich nicht nur damit zu tun, dass weiblicher Transvestitismus (wie auch weibliche Homosexualität) „unsichtbarer" war, sondern dass eben - so auch Wahls Befund für Österreich - „Männer in Frauenkleidern und Transsexuelle in der Dokumentation, die die nationalsozialistischen Verfolger hinterlassen haben, nur recht selten auf(tauchen)“. So wurden für Österreich in der Zeit der NS-Herrschaft bislang - wohl aufgrund der Untersuchung von primär Strafprozessakten auch nur männliche Transvestiten bzw. Transgender-Personen erhoben. ${ }^{43}$

Ein veritables Forschungsdesiderat stellt daher das Themenfeld der Erteilung von polizeilichen Genehmigungen für das Tragen der Kleidung des Gegengeschlechts und Vornamensänderungen von "Transvestiten" sowie der juristischen Geschlechtsumwandlung dieser Personen durch Korrektur des Personenstands in der "Ostmark“ nach reichsdeutschem Vorbild bzw. reichsdeutscher Rechtslage dar. Für die Zeit der NS-Herrschaft liegen überdies bislang nicht einmal Studien zur Implementierung des deutschen Namensänderungsrecht von 1938 in Österreich

\footnotetext{
${ }^{40}$ HeRrN, Transvestitismus 355.

${ }^{41}$ HACKER, Frauen 56f; HACKER, Ordnung 67-70, 192-202.

${ }^{42}$ WAHL, Verfolgung 73-78.

${ }^{43}$ Ebd. 71f.
} 
vor, ${ }^{44}$ wodurch sich jedoch Impulse und auch Quellenfunde für das Forschungsfeld „Transvestitismus" ergeben könnten, wurde doch etwa der Fall der Emma K. als "Musterakt" in den Beständen des Wiener Stadt- und Landesarchivs zu Namensänderungen in der NS-Zeit aufgefunden.

\section{Rechtsgrundlagen}

Da nach der Machtübernahme der Nationalsozialisten 1933 hinsichtlich der Behandlung weiblicher "Transvestiten"- wie zu zeigen sein wird offenbar kein Paradigmenwechsel stattfand, sondern diese vielmehr auf die einschlägige, noch auf die Endphase des Deutschen Kaiserreichs zurückgehende Praxis der Weimarer Republik aufbauten, wird diese, gestützt auf die grundlegenden Arbeiten Herrns, zunächst skizziert, bevor auf die Spezifika der österreichischen Rechtslage nach dem "Anschluss" 1938 eingegangen wird.

\subsection{1. "Transvestitenschein"}

Gegen das Tragen der Kleidung des Gegengeschlechts gab es sowohl im Kaiserreich als auch in der Weimarer Republik keine spezifische Handhabe. Nur die Straftatbestände der Störung der öffentlichen Ordnung oder der Erregung öffentlichen Ärgernisses konnten in Anwendung gebracht werden, was aber, so Hirschfelds juristischer Berater Eugen Wilhelm 1909, eine tatsächliche „Belästigung des Publikums, eine Störung der Öffentlichkeit" voraussetzte. Daher konnte das Cross-Dressing "an und für sich [...] nicht als grober Unfug bestraft werden", auch nicht das Ausgehen in den Kleidern des Gegengeschlechts, „sofern dies dem Publikum gar nicht auffällt und keine Ärgerniserregung, kein unliebsames Aufsehen usw. in der Öffentlichkeit

\footnotetext{
${ }^{44} \mathrm{Vgl}$. dazu erstmals ReIter-ZatLouKaL, Entschleierung .
}

entsteht" ${ }^{45}$ In diesem Sinne hatte auch das Berliner Polizeipräsidium bereits 1911 das Gesuch einer Frau beschieden: „Nach dem Gesetz und der Rechtsprechung der Gerichte ist das Tragen von Männerkleidern durch eine Frau nur strafbar, wenn die öffentliche Ordnung zum Beispiel dadurch, dass ein Menschenauflauf entsteht, oder in ähnlicher Weise gestört wird. Wenn Sie also Männerkleidung tragen, so haben Sie vor allen Dingen dafür zu sorgen, dass das Tragen solcher Kleidung zu keinen Misshelligkeiten führt und die öffentliche Ordnung dadurch keineswegs gestört wird. Nur wenn in letzter Hinsicht ungünstige Tatsachen bekannt würden, müsste Ihnen das Tragen von Männerkleidern verboten werden." 46

Eine Dienstanweisung des Berliner Polizeipräsidiums 1922, die nach Ansicht der „Deutschen Strafrechts-Zeitung" "den rechtlichen und psychologischen Gesichtspunkten außerordentlich verständig Rechnung [trug]“, betonte ganz allgemein, dass die Fälle, die „Anlaß zum polizeilichen Einschreiten" bieten würden, durchaus „selten“ seien. Die Transvestiten blieben nämlich weitgehend „,von der Öffentlichkeit unbeachtet", weil sie "sich in ihrem ganzen Wesen meist so sehr dem anderen Geschlecht nähern, daß sie diesem vom Publikum ohne weiteres dazu gezählt und nicht beachtet werden“. ${ }^{47}$ Dennoch lege die Kriminalpolizei "Wert darauf", von solchen Fällen Kenntnis zu erhalten, „bei denen Transvestiten aus irgendeinem Anlasse festgestellt werden“. Die Dienstanweisung betonte überdies, dass der Transvestitismus „im allgemeinen keine kriminelle Bedeutung hat und die vielfach verbreitete Meinung, es handle sich bei den verkleideten Personen um verkapp-

\footnotetext{
${ }^{45}$ WILHELM, Rechtliche Stellung 54f, zit. n. HERRN, Schnittmuster 66.

${ }^{46}$ Berliner Tageblatt 1911, zit. n. HERRN, Schnittmuster 68.

47 Über die Behandlung der sog. Transvestiten 171; vgl. auch HERRN, Schnittmuster 136.
} 
te Verbrecher (Taschendiebe, Spione, Mädchenhändler usw.), nicht zutrifft". Auch stelle sich die lange Zeit vorherrschende Annahme, dass diese Personen "durchweg als Homosexuelle anzusprechen" seien, nach "neueren Erfahrungen“ als "nicht mehr haltbar" dar. Es bestehe daher die Pflicht einer "schonenden Behandlung" der Transvestiten, sofern sie nicht der "männlichen Prostitution zuzuzählen" seien, und auch gegen diese könnte mit "Schutzhaft" nur ",bei anstoßerregendem Umherstreifen in der Öffentlichkeit eingeschritten werden “. ${ }^{48}$

Ausdruck dieser "schonenden Behandlung“ war der bereits seit 1909 vergebene sog. Transvestitenschein, ${ }^{49}$ der ",eine amtlich beglaubigte Bestätigung“ darstellte, „dass jene Person der Polizei als Männer- respektive Frauenkleider tragend bekannt sei, weshalb von Maßnahmen abgesehen werden sollte". ${ }^{50}$ Damit war ihnen implizit erlaubt, polizeilich unbehelligt in der Öffentlichkeit die Kleidung des Gegengeschlechts zu tragen, mussten doch Männer und Frauen ohne derartige Erlaubnis jedenfalls mit einer polizeilichen Verwarnung rechnen. ${ }^{51}$

Beim ersten Fall eines derartigen Scheins in Berlin 1908/09 handelte es sich um eine Frau (Katharina T.), die sich "vollkommen als Mann“ fühlte und schon lange Zeit in Männerkleidern gearbeitet hatte, wobei niemand nach "ihrer Haltung und ihren Bewegungen" vermutet habe, "dass er in ihr ein Weib vor sich habe". Sie bat das Polizeipräsidium, „keinen Einspruch dagegen zu erheben, dass sie in männlicher Kleidung gehe", 52 was ihr auch bewilligt wurde. ${ }^{53}$

\footnotetext{
${ }^{48}$ Ebd.

${ }^{49}$ Siehe einen derartigen Transvestitenschein bei HERRN, Schnittmuster 138, einen Transvestitenpass ebd. 130.

${ }^{50}$ HERRN, Transvestitismus 332.

${ }^{51}$ KRAFFT-EBING, Psychopathia sexualis, Beobachtung $167,313 f$.

52 HIRSCHFELD, Transvestiten 192f., 194, 196.

${ }^{53}$ KRAFFT-EBING, Psychopathia sexualis, Beobachtung 170, 317, berichtet allerdings auch von einer unter
}

Wie schon dieser Fall zeigt, ist bei Frauen, die sich um einen "Transvestitenschein" (und die Vornamensänderung) bemühten, das Motiv, ungestört als Männer einem Erwerb nachgehen zu könnten, nicht zu vernachlässigen, was umgekehrt bei Männern keine Rolle spielte, da in diesem Fall das Tragen von Kleidern des Gegengeschlechts keine beruflichen Vorteile bot.

Unterstützt wurden die Frauen, die sich um derartige Bewilligungen bemühten, von Hirschfeld, der sich schon 1910 generell dafür aussprach, dass „man die Erlaubnis, die Tracht des anderen Geschlechts öffentlich anlegen zu dürfen, von einem Gesuch abhängig macht, das die Personen, welche dies wünschen, der Polizei einzureichen haben". Das Ansuchen sollte insbesondere "die Gründe enthalten, auf die sich die Forderung stützt" sowie ein ärztliches Attest. ${ }^{54}$ In einem dieser Gutachten führte Hirschfeld wegweisend als Begründung für die dringende Gebotenheit einer derartigen Erlaubnis zum Tragen von Männerkleidern aus, dass die betroffene Frau einerseits „in Frauenkleidern einem verkleideten Manne gleicht und dadurch ohne ihren Willen bei andern Anstoss und Aergernis erregt", und andererseits „ihre Gesundheit unter dem Tragen von Frauenkleidern leidet" ${ }^{\prime \prime}{ }^{55}$ Insbesondere wurde in diesen Gutachten betont, dass es im Interesse des Gesundheitszustandes des Antragstellers bzw. der Antragstellerin sei, einen "Transvestitenschein“ auszustellen. Weiters wurde in diesen Gutachten argumentiert, dass die TransvestitInnen in der Kleidung ihres biologischen Geschlechts so aussähen, als trügen sie die Kleidung des Gegengeschlechts, und nur durch das Tragen der Kleidung des "anderen“ Geschlechts würden sie kein Aufsehen erregen bzw. nicht auffallen und sich so gleichsam der gesellschaftlich vorgeschriebenen Kleiderord-

Kuratel gestellten Patientin, die von zu Hause „in Männerkleidern durchging“.

${ }^{54}$ HIRSCHFELD, Transvestiten 363.

${ }_{55}$ HIRSCHFELD, Geschlechts-Umwandlungen 13. 
nung unterwerfen können. Daher sei der „Transvestitenschein“ ein „Hilfsmittel für den Notfall“. ${ }^{56}$

Da viele dieser Gutachten veröffentlicht wurden, dienten sie in weiterer Folge als Vorlage für andere derartige Gutachten ${ }^{57}$ und wohl auch als Leitfaden für die Begründungen der Anträge auf „Transvestitenscheine“. Wie Herrn feststellt, bekräftigten auch die Transvestiten ihrerseits Hirschfelds Konstruktion des Phänomens Transvestitismus, „indem sie ihre Biographien nach dem vorgegebenen Muster beschrieben und ihre Neigung als, unwiderstehlichen Drang' bezeichneten", womit Hirschfelds Publikationen auch zur „Identifikationsliteratur" für TransvestitInnen wurden. 58

Interessanterweise traten allerdings Männer zunächst nicht an Hirschfeld wegen einer solchen polizeilichen Erlaubnis heran, wohl weil das Tragen von Kleidern des Gegengeschlechts für sie nicht eine Frage des beruflichen Fortkommens, sondern „nur“ ein rein psychisches Verlangen darstellte. ${ }^{59}$ Die erstmalige Ausstellung eines "Transvestitenscheins" für einen Mann erfolgte in München um 1912, es folgte Potsdam 1913, aber auch in anderen Städten kam es in den 1920er-Jahren zu derartigen Genehmigungen. Herrn zufolge dürfte der „Transvestitenschein" schließlich bald reichsweit anerkannt gewesen sein, Verweigerungen seitens der dafür zuständigen lokalen Polizeibehörde seien fast nie vorgekommen. Die vermutlich unbefristeten Scheine waren hinsichtlich ihrer Gültigkeit überdies nicht auf den Ausstellungsort beschränkt, sondern wurden vielmehr auch in anderen Städten zumeist erneuert. ${ }^{60}$

Wie Herrn konstatiert, hatte sich durch die Praxis der „Transvestitenscheine“ freilich „eine

\footnotetext{
${ }^{56}$ Vgl. HERRN, Schnittmuster 84.

${ }^{57}$ HIRSCHFELD, Sexualpathologie 160.

${ }^{58}$ HERRN, Schnittmuster 68f.

${ }^{59}$ MAK, Passing Women 391.

${ }^{60}$ HERRN, Schnittmuster 140, 126.
}

doppelte Abhängigkeit der Transvestiten (etabliert), einerseits von ihrer Beglaubigung durch Mediziner, andererseits von staatlichen Ordnungsinstanzen wie Justiz und Polizei“ ${ }^{61}$

\subsubsection{Vornamensänderung und Personen- standskorrektur}

Vielen Transgenderpersonen ging es aber nicht nur um das Tragen der Kleidung des Gegengeschlechts, sondern sie wollten auch juristisch als Angehörige des „anderen“ Geschlechts gelten, wozu die Namensänderung, aber auch die Korrektur des Personsstands (und damit verbunden auch die Möglichkeit einer Verehelichung) zählte. Die Vornamensänderung war allerdings in der Weimarer Republik zunächst für TransvestitInnen, also biologisch eindeutig einem der beiden Geschlechter zuordenbare Personen, nicht möglich. Die Vornamens- und Personenstandskorrektur war vielmehr "Zwittern" bzw. „Hermaphroditen" vorbehalten, für die seit Ende des 18. Jahrhunderts, als sich das biologische Zweigeschlechtermodell durchsetzte, die vom kanonischen Recht entwickelte und in der frühen Neuzeit von den Partikularrechten übernommene Wahl des Geschlechts mittels (einmaligem) Eidschwur ${ }^{62}$ untersagt wurde. Hatte noch das preußische Allgemeine Landrecht von 1794 dem "Zwitter" das Recht eingeräumt, zu wählen, ,zu welchem Geschlecht er sich halten wolle", 63 so sollte nach dem Sächsischen Bürgerlichen Gesetzbuch von 1863/65 eine „Person, deren Geschlecht zweifelhaft ist, [...] dem bei ihr vorherrschenden Geschlecht beigezählt werden".64 Das deutsche Bürgerliche Gesetzbuch von 1900 ent-

\footnotetext{
${ }^{61}$ HerRn, Transvestitismus 332.

62 WACKE, Hermaphroditen 884f; HiRSCHAUER, Konstruktion $69 f$.

${ }^{63}$ Nach dem zurückgelegten 18. Lebensjahr, vorher bestimmten die Eltern, zu welchem Geschlecht ein "Zwitter" erzogen werden sollte, vgl. WACKE, Hermaphroditen 887 .

${ }^{64}$ So $\S 46$ des sächsischen BGB von 1863/65, vgl. ebd. 883.
} 
hielt überhaupt keine Vorschrift über "Zwitter" mehr, war doch nach Ansicht von dessen Verfassern ,jeder sog. Zwitter entweder ein geschlechtlich mißgebildeter Mann oder ein geschlechtlich mißgebildetes Weib" ${ }^{65}$ Daher wurde die Bestimmung des „wahren Geschlechts“66 derartiger als „Pseudohermaphroditen“ gesehenen Personen nun nach den äußeren und inneren Geschlechtsmerkmalen des überwiegenden Geschlechts vorgenommen. Im Zuge seiner Gutachtertätigkeit setzte sich Hirschfeld allerdings dafür ein, die übrigen körperlichen und psychischen Eigenschaften der Personen und ihren Wunsch bei der Geschlechtszuweisung ebenfalls zu berücksichtigen, was er ab etwa 1912 auch für die TransvestitInnen forderte.

Nachdem Hirschfelds erster Versuch 1909, für eine weibliche Transvestitin einen Vornamenswechsel zu erreichen, gescheitert war, ging er in weiterer Folge den Weg, in solchen Fällen das biologische Geschlecht als uneindeutig zu beschreiben und die Betroffenen als "Zwitter" auszuweisen. ${ }^{67}$ Eine derartige medizinische Begründung eines Vornamenwechsels gelang 1912 im Fall der Passing Woman Louise Sch., ${ }^{68}$ die Männerkleidung trug, weil sie sich als Mann fühlte (und nicht aufgrund eines „unwiderstehlichen Dranges“). ${ }^{69}$ Tatsächlich sprach in diesem Fall anatomisch kaum etwas für den Befund "Zwitter", da keine Zwitterform der äußeren Geschlechtsteile vorlag und Hirschfeld männliche Keimdrüsen nur vermutete, vielmehr beschrieb Hirschfeld wohl eher ein sog. "Mannweib" und betonte den "absolut männlichen“ äußerlichen und psychischen "Gesamteindruck": 70 "Fernstehende“ würden „an ihrer in

\footnotetext{
${ }^{65}$ Motive I 26, zit. n. ebd. 870.

${ }^{66}$ Foucault, Geschlecht; auch MehlmanN, Körper $86 f$.

${ }^{67}$ HeRrN, Geschlecht.

${ }^{68}$ HiRSCHFELD, Geschlechts-Umwandlungen 9 ff.

${ }^{69}$ Das Gutachten ist abgedruckt bei HERRN, Schnittmuster $85 \mathrm{ff}$.

70 SCHMERSAHL, Medizin 157-189.
}

Frauenkleidern sehr auffallenden Erscheinung Anstoß (nehmen)" und hielten sie "gewöhnlich für einen verkleideten Mann“. Auch "die Kinder auf der Straße verspotten sie als solchen“, darüber hinaus seien auch ihr Habitus und ihre „Neigungen“ bzgl. sportlicher Betätigung ",ausgesprochen männlich" und sie rauche "leidenschaftlich gern, besonders Zigarren“. Vor allem daraus folgerte Hirschfeld, dass hier ein „Fall von Zwitterbildung nicht sowohl in rein äußerlichen als vielmehr in tieferem Sinne" vorliege, bei „dessen Gesamtgeschlechtlichkeit das Männliche entschieden überwiege". Es sei daher in "Anbetracht der ganzen Sachlage dringend geboten", dass Louise Sch. nicht nur die Erlaubnis zum Tragen von Männerkleidern, sondern auch "die Genehmigung erteilt wird, ihren weiblichen Vornamen [...] umändern zu dürfen, weil der weibliche Vorname sie beim Tragen männlicher Kleidung fortgesetzt in Konflikte bringe und es ihr schwer, wenn nicht unmöglich machen würde, eine Stelle zu erhalten. ${ }^{\prime 71}$ In diesem Fall wurde auch der Personenstand geändert und Louise Sch. ehelichte in weiterer Folge nun als Louis ihre Freundin. Wie es der Jurist Eugen Wilhelm 1914 kommentierte, seien durch die juristische Geschlechtsumwandlung nun „ihre früheren abnormen transvestitischen Neigungen und ihr ,perverser' Sexualtrieb normal geworden ${ }^{\prime \prime}, 72$ und dies alles allein aufgrund der Selbstzuordnung und mit Hilfe eines Gutachtens ohne operative Eingriffe - wie dies auch bei Mathilde/Mathias Robert S. der Fall sein sollte. Weitere derartige Versuche Hirschfelds, eine juristische Geschlechtsumwandlung mit der Begründung eines "seelischen Zwittertums“73 $\mathrm{zu}$ erreichen, scheiterten allerdings.

\footnotetext{
${ }^{71}$ HiRSCHFELD, Geschlechts-Umwandlungen $13 \mathrm{f}$.

72 WILHELM, Transvestiten 402, zit. n. HERRN, Schnittmuster 91.

${ }^{73}$ WILHELM, Geschlechtsbestimmung; vgl. HERRN, Schnittmuster 90 .
} 
Auch dem Versuch von Katharina T., der Inhaberin des ersten "Transvestitenscheins" in Berlin, eine Vornamensänderung zu erreichen, war kein Erfolg beschieden, weil sie eindeutig dem weiblichen Geschlecht zuzuordnen war. Zwar argumentierte sie, den Beweis erbracht zu haben, dass sie sich "als Mann ernähren könnte", wenn sie „nicht überall wegen des weiblichen Vornamens Anstoß und Aufsehen erregte". Ihr berufliches „Fortkommen“ würde dadurch „in jeder Weise durch den Vornamen erschwert", sie selbst ,schwebe in steter Angst vor einer Entdeckung“, wenn sie sich irgendwo in Stellung befinde. Dieser Zustand reibe sie "gesundheitlich völlig auf“, auch habe sie „mit den Behörden viel Auseinandersetzungen",74 weshalb sie die Änderung ihres weiblichen Vornamens in einen männlichen beantrage, welchem Ansinnen jedoch trotz Hirschfelds Unterstützung nicht entsprochen wurde.

1918 berichtete Hirschfeld schließlich, dass sich Transvestiten entweder neutrale Namen zulegten (z.B. Toni für Anton oder Antonie oder Gert für Gertrud oder Gerhard) oder ihren Vornamen in Ausweispapieren nur mit dem Anfangsbuchstaben verzeichneten. ${ }^{75}$ Seit November 1919 konnte dann in Preußen zwar der Familienname durch das zuständige Amtsgericht geändert werden. ${ }^{76}$ Die Anträge „von mehreren Transvestiten“ bzw. biologischen Frauen, „ihren weiblichen Vornamen dem inneren und äußeren Seelenleben entsprechend in einen männlichen umzugestalten",77 wurden vom Gericht allerdings weiter abgelehnt, die Angelegenheit jedoch dem Justizminister vorgelegt. Dieser teilte 1920 dem Anwalt der Transvestitinnen, Walther Nieman, mit, dass es keinen Erlass gebe, „der Personen

\footnotetext{
${ }^{74}$ Zit. n. MAK, Passing Women 389.

${ }^{75}$ HIRSCHFELD, Sexualpathologie 171.

${ }^{76}$ Verordnung betreffend die Änderung von Familiennamen vom 3.11. 1919, Preußisches Gesetzblatt 177.

77 NiEMANN, Salomonisches Urteil 146.
}

zweifelhaften Geschlechts die generelle Ermächtigung erteilt, einen neutralen Vornamen anzunehmen“. Bei „Gesuchen dieser Art" pflege er sich gemäß der Allgemeinen Verfügung vom 21. April $1920^{78}$,die Entscheidung vorzubehalten und die Bewilligung des Gesuchs von der Wahl eines neutralen Vornamens abhängig zu machen, über dessen Geeignetheit“ er „,in jedem Einzelfalle befinden werde". Er lehne es daher $\mathrm{ab}$, seinerseits „auf Grund ärztlicher Gutachten darüber eine Entscheidung $\mathrm{zu}$ treffen, ob eine Person zweifelhafter Geschlechtsbildung vorwiegend als Mann oder vorwiegend als Weib anzusprechen" sei. Allerdings erklärte er seine Bereitschaft, ,[s]oweit es das äußere Fortkommen solcher Personen im Einzelfall dringend erheischt", diese „zur Führung eines neutralen Vornamens $\mathrm{zu}$ ermächtigen, der sowohl eine weibliche, wie eine männliche Person bezeichnen kann. (Theo, Alex, Toni, Geerd u. dergl. mehr) “. ${ }^{79}$ Nieman bezeichnete diese Entscheidung des Justizministers als einen, „dem salomonischen Urteil gleich, [...] gerechten, allen Verhältnissen Rechnung tragenden Spruch", da der Justizminister den TransvestitInnen ,wweder prinzipiell seinen Schutz versagt, noch ihnen das unbeschränkte Recht auf Änderung des Namens erteilt" habe. ${ }^{80}$ Voraussetzung einer derartigen Namensänderung war jedenfalls ein positives Gutachten, wobei die vom (1919 von Hirschfeld gegründeten) Institut für Sexualwissenschaft erstellten Gutachten die Strategie verfolgten, die AntragstellerInnen durchwegs als Personen zweifelhaften Geschlechts bzw. als Vor-

\footnotetext{
${ }^{78} \S 2$ : „Der Justizminister behält sich vor, über Anträge von grundsätzlicher Bedeutung oder in sonst geeigneten Fällen selbst zu entscheiden“, Justiz-Ministerial-Blatt für die preußische Gesetzgebung und Rechtspflege 82 (1920) 166, vgl. auch HERRN, Schnittmuster 128. ${ }^{79}$ Zit. n. HERRN, Schnittmuster 128.

${ }^{80}$ NiEMAN, Salomonisches Urteil 146.
} 
stufe des Hermaphrodismus darzustellen, ${ }^{81}$ um die Namensänderung und Personenstandskorrektur erwirken zu können.

Bis 1920 hatte Nieman eigenen Aussagen zufolge jedenfalls bereits „in zirka 6 Fällen eine Änderung bisheriger weiblicher Vornamen in Alex und Gerd erlangt". ${ }^{82}$ Von der Möglichkeit der Vornamensänderung machten zunächst also vorwiegend weibliche Transvestiten Gebrauch, wobei das gesamte Ausmaß bislang unbekannt ist. Hirschfeld sprach 1924 von einer "grössere[n] Reihe männlicher und weiblicher Transvestiten", die von "diesem Entgegenkommen" Gebraucht gemacht hätten, ${ }^{83}$ Herrn zufolge dürfte es sich allerdings um eine durchaus „überschaubare Zahl gehandelt" haben. In den von ihm beschriebenen Fällen lebten die Frauen jedenfalls schon lange in Männerkleidern und waren als Männer nie irgendwie aufgefallen. ${ }^{84}$

Die Anträge wurden Nieman zufolge „im Allgemeinen schnell erledigt und eine Änderung des Vornamens meist in einigen Wochen durchgeführt". ${ }^{\prime 85}$ Danach erfolgte eine Veröffentlichung der Vornamensänderungen im „Deutschen Reichsanzeiger und Preußischen Staatsanzeiger", wodurch es freilich auch zu einem unfreiwilligen Outing der TransvestitInnen kam.

$\mathrm{Ob}$ auch stets die Geburtsurkunde korrigiert, also der Personenstand der betreffenden Person geändert wurde, ist unklar, ${ }^{86}$ und damit auch die Frage nach einer möglichen Eheschließung die-

\footnotetext{
${ }^{81}$ Siehe den Fall Amanda Balitzki, HiRsCHFELD, Sexualpathologie 21-23; auch HERRN, Schnittmuster 131.

82 NIEMANN, Salomonisches Urteil 146.

${ }^{83}$ HIRSCHFELD, Sexualität und Kriminalität 40.

${ }^{84}$ HERRN, Schnittmuster 129.

${ }^{85}$ NiEMAN, Salomonisches Urteil 146.

${ }^{86}$ Eine derartige Änderung wurde aber im Fall Amanda/Amandus Balitzki wegen Täuschung durch die Antragstellerin ebenso widerrufen wie die Ermächtigung zur Führung eines männlichen Vornamens und die Genehmigung zum Tragen männlicher Kleidung, HIRSCHFELD, Sexualpathologie 21-23; siehe HERRN, Schnittmuster 131ff.
}

ser Personen. ${ }^{87}$ Offenbar jedoch wurden derartige Personenstandskorrekturen jedenfalls nicht von einer operativen Anpassung des Körpers von Transgenderpersonen abhängig gemacht, wenngleich medizinische Eingriffe seit 1911/12 in Form von (Selbst)Kastrationen und sonstigen (Selbst)Operationen männlicher Transvestiten wie auch Entfernungen der Brüste und Gebärmutter, v.a. durch Ärzte, bei Transvestitinnen berichtet werden. ${ }^{88}$ Ging es zunächst nur um die Tilgung der sichtbaren Zeichen des Herkunftsgeschlechts, so sind medizinische Eingriffe zum Zweck der Ausformung der Geschlechtsorgane des „anderen“ Geschlechts - nach den ersten Versuchen 1920/21 für Mann-zu-Frau-Umwandlungen - v.a. seit Ende der 1920er-Jahre nachgewiesen. ${ }^{89} \mathrm{Da}$ es für Frauen erst seit den 1970er-Jahren entsprechende plastisch-chirurgische Möglichkeiten gab, beschränkten sich bis dahin also bei "Transvestitinnen“ die Eingriffe weiterhin auf Entfernung der Brüste, Gebärmutter und Ovarien, über die Häufigkeit der Operationen liegen allerdings keine Angaben vor. ${ }^{90}$

\subsection{NS-Zeit}

Wie Herrn betont, liegen keine "[s]ystematische[n] Untersuchungen über Kontinuitäten im Umgang mit Transvestiten aus der Weimarer Zeit im Nazi-Deutschland sowie über entsprechende Brüche" vor. ${ }^{91}$ Es habe nach der Machtübernahme 1933 "keine einheitliche Strategie“ gegeben, die Transvestiten standen aber „unter

\footnotetext{
${ }^{87}$ Wie der von Herrn angeführte Versuch einer Eheschließung eines weiblichen Transvestiten ausging, deren Vornamensänderung von Bertha auf Berthold bewilligt worden war, wird nicht berichtet, das Standesamt weigerte sich jedenfalls, die Anmeldung zur Trauung entgegenzunehmen, HERRN, Schnittmuster 131.

${ }^{88}$ Ebd. $103 \mathrm{ff}$.

${ }^{89}$ Ebd. 167ff, insbes. 195ff.; vgl. auch RUNTE, Operationen 400 .

${ }^{90}$ HERRN, Schnittmuster 200.

${ }^{91}$ Ebd. 157.
} 
dem Generalverdacht der Homosexualität"92 bzw. trugen die Beweislast der Heterosexualität. Insbesondere wurde das Tragen von Frauenkleidern durch Männer von den Nationalsozialisten als klares Indiz für Homosexualität und damit Staatsfeindlichkeit gewertet, 93 aber auch Frauen in Männerkleidung standen unter der Annahme der Homosexualität. ${ }^{94}$

Bekannt ist freilich, dass Hirschfeld ein Feindbild für die Nationalsozialisten war und blieb: Sein Institut wurde 1933 geschlossen, die Institutsbibliothek fiel der Bücherverbrennung auf dem Berliner Opernplatz zum Opfer, Hirschfeld selbst starb 1935 im Exil. Klar liegt auch zu Tage, dass die Geschlechterdichotomie im Nationalsozialismus eine besondere Verfestigung fand. So sah es z.B. Heinrich Himmler als „Katastrophe an, wenn wir die Frauen so vermännlichen, dass mit der Zeit der Geschlechtsunterschied, die Polarität verschwindet“. Überdies galten ihm „,[a]lle Dinge, die sich auf dem geschlechtlichen Sektor bewegen", nicht als "Privatangelegenheit eines einzelnen, sondern sie bedeuten das Leben und Sterben des Volkes.“95

Die Zuständigkeit für „Transvestiten“ lag einerseits bei der Geheimen Staatspolizei (Gestapo), wo seit Oktober 1934 ein Sonderdezernat Homosexualität im „Geheimen Staatspolizeiamt" bestand, ${ }^{96}$ andererseits wurde 1936 die „Reichszentrale $^{97}$ zur Bekämpfung der Homosexualität und

\footnotetext{
${ }^{92}$ HERRN, Ver-körperungen.

${ }^{93}$ HerRn, Schnittmuster 159.

${ }^{94}$ Siehe derartige Fälle aus 1940 bei HERRN, Transvestitismus 355f.

${ }^{95}$ Dann sei „der Weg zur Homosexualität nicht weit“, Himmler am 18.2. 1937 vor SS-Gruppenführern in Bad Tölz, zit. n. ScHOPPMANN, Sexualpolitik 26.

${ }^{96}$ WAGNER, Volksgemeinschaft 249.

${ }^{97}$ Reichszentralen übernahmen „die exekutive Tätigkeit des Reichskriminalpolizeiamtes selbst sowie die Führung der wichtigsten zentralen Modus operandiSammlungen“ und entsprachen „in ihrem Zuschnitt den Spezialkommissariaten einer Großstadtkripo". Weitere bedeutende Reichzentralen bestanden zur Bekämpfung von Geldfälschungen, „internationaler
}

Abtreibung" eingerichtet. Sie war dem Reichskriminalpolizeiamt (als „Generalstab der deutschen Kriminalpolizei“"98) zugehörig und unterstand seit 1939 dem von Reinhard Heydrich geleiteten Reichssicherheitshauptamt. Diese konkurrierende Kompetenz blieb auch nach 1936 bestehen, als Himmler sowohl Chef der Gestapo als auch der Kripo wurde. ${ }^{99}$ Die Reichszentrale war konkret zuständig für die „Mitwirkung bei der Ausgestaltung der sicherheitspolizeilichen Behandlung sexuell Entarteter", wie der „Transvestiten, Fetischisten u.a." ${ }^{100}$ Sie überprüfte dementsprechend auch „einige Fälle von Transvestismus“, bei denen „eine zufriedene Lösung seitens der zuständigen Behörden nicht erfolgt war".101

\subsection{1. "Transvestitenschein"}

Trotz der Ächtung Hirschfelds und der Zerstörung seines Instituts wurden „Transvestitenscheine" aus der Weimarer Republik in der NSZeit verlängert und sogar neue ausgestellt. So berichtet Herrn von Scheinen für zwei männliche Transvestiten aus den Jahren 1934 und 1937.102 Bezüglich weiblicher Transvestiten liegen nach bisherigem Erkenntnisstand ebenfalls nur wenige Fälle einer Verlängerung bzw. Neuerteilung vor. So führt Herrn den Fall der arbeitslosen Gertrud W. ${ }^{103}$ an, der 1935 zunächst die Verlängerung ihres Anfang 1933 ausgestellten "Transvestitenscheins" genehmigt, dann

Taschendiebe“, des "Zigeunerunwesens“, „reisender und gewerbsmäßiger Betrüger und Fälscher" sowie der Jugendkriminalität, vgl. WAGNER, Volksgemeinschaft 238; siehe zur Reichszentrale auch JELLONEK, Homosexuelle 122ff.

98 WAGNER, Kriminalisten 76.

${ }^{99}$ Der Geschäftsverteilungsplan datiert allerdings frühestens auf September 1941, vgl. ebd. 125; siehe auch JELLONEK, Fahndungs- und Ermittlungsmethoden $348 \mathrm{f}$.

100 Vgl. GRAU, Homosexualität 145, 167.

101 Zit. n. SCHOPPMANN, Sexualpolitik 198.

102 HerRN, Schnittmuster 161.

${ }^{103}$ HerRN, Transvestitismus 358f. 
allerdings die Namensänderung abgelehnt wurde. Grund der Verweigerung war offenbar das von der Gestapo bei einem bekannt "gnadenlosen" Sachverständigen eingeholte gerichtsmedizinisch-psychiatrische Gutachten über die Notwendigkeit der Beibehaltung des „Transvestitenscheins" und der Vornamensänderung, das Gertrud W. eindeutig „dem Befund nach zum weiblichen Geschlecht" zugeordnet hatte. Auch der "Transvestitenschein“ wurde Gertrud W. nun entzogen und sie musste schriftlich ihr Einverständnis erklären, falls sie künftig Männerkleidung trage, sich so zu bewegen, dass sie kein öffentliches Ärgernis errege.

Bei der Sanktionierung des „verbotswidrigen Tragens von Männerkleidern" spielte es offenbar eine Rolle, ob der Verdacht einer lesbischen Betätigung vorlag. Im von Herrn beschriebenen Fall der Agnes S., ${ }^{104}$ die in Berlin 1939 ohne „Transvestitenschein“ in Männerkleidung Äpfel verkauft und bei der polizeilichen Einvernahme angegeben hatte, zwar lesbisch zu sein, aber seit mehreren Jahren keine "geschlechtlichen Beziehungen zu Frauen" mehr unterhalten zu haben, begnügte sich die Polizei zunächst mit dem Versprechen der Agnes S., zwar nicht sofort, aber „in kürzester Zeit" die Bekleidung umzustellen, um ihre Kundschaft, die sie nur als Mann kenne, langsam an das neue Erscheinungsbild zu gewöhnen. Als sie im Jahr darauf wieder in "ausgesprochener Männerkleidung“, sodass ,jedermann der Ansicht war, daß es sich um eine männliche Person handelte", aufgegriffen wurde, konstatierte die Polizei nun, dass Agnes S. "aus unsittlichen Motiven Männerkleidung trägt". Nun hatte sie zur Kenntnis zu nehmen, dass sie „in Zukunft nicht mehr in Männerkleidung auf der Straße [... ihrem] Gewerbe nachgehen“ dürfe, ansonsten sie mit "staatspolizeilichen Maßnahmen zu rechnen" habe. Agnes S. sollte auch „entsprechend“ überwacht werden.

${ }^{104}$ Ebd. 356f.
Auf der anderen Seite wurde 1938 die Arbeiterin Erna K., ${ }^{105}$ die überführt worden war, „,bis in die letzte Zeit Männerkleidung getragen zu haben, obgleich ihr die bisher hierzu erteilte Genehmigung im Jahre 1933 entzogen worden“ war, auf Anordnung Reinhard Heydrichs in "Schutzhaft" genommen, weil sie „durch ihr Verhalten die öffentliche Sicherheit und Ordnung unmittelbar gefährdet". Nach fast neun Monaten im FrauenKonzentrationslager Lichtenburg/Politische Abteilung erfolgte ihre Entlassung und die Erteilung einer „einstweiligen Genehmigung“ zum Tragen von Männerkleidung. Ihr endgültiger "Transvestitenschein" enthielt die Auflage, dass sie öffentliche Bedürfnisanstalten, Bäder u. dgl. in Männerkleidung nicht aufsuchen" dürfe, eine offenbar übliche Bedingung, wie am Beispiel Emma/Emil Rudolf K. zu zeigen sein wird. „Absurderweise", so Herrn, wurde allerdings damit Erna K. verboten, ,jene Orte aufzusuchen, die als Kontaktstellen homosexueller Männer im Visier der Verfolger standen“", hätte doch möglicherweise eine dortige „Entdeckung ihres Geschlechtes öffentliches Aufsehen erregt". Überdies erhielt Erna K., die sich nach dem Bericht der Polizei „einwandfrei geführt“ hatte, nun im Dezember 1938 die Genehmigung, hinkünftig den Vornamen Gerd zu führen, sollte aber ebenfalls polizeilich überwacht werden.

Diese verschiedenen Fälle zeigen nicht nur „eine gewisse Willkür" der Behörden,106 sondern für Herrn werfen die Fälle der Erna K. und Gertrud W. auch die Frage auf, inwiefern der "unterschiedliche Umgang mit dem Anliegen der Transvestiten und Transvestitinnen auf eine veränderte Praxis zwischen 1935 und 1940 deutet". ${ }^{\prime 107}$

\footnotetext{
${ }^{105}$ Ebd. 357.

106 Ebd. 360.

107 HERRN, Schnittmuster 164.
} 


\subsubsection{Vornamensänderung und Personenstandskorrektur}

Was die Vornamensänderung anbelangt, so wurde mit dem Gesetz über die Änderung von Familiennamen und Vornamen vom 5. Jänner $1938^{108}$ der Reichsminister des Innern ermächtigt, Vorschriften über die Führung von Vornamen zu erlassen und von Amts wegen die Änderung von Vornamen, die diesen Vorschriften nicht entsprachen, zu veranlassen. Mit Runderlass vom 18. August $1938^{109}$ ergingen die Richtlinien für Vornamensänderungen, für die ein „wichtiger Grund“ vorliegen musste. Wurde eine derartige Namensänderung bewilligt, dann hatte der Geburtsbucheintrag mittels Randvermerk durch den Standesbeamten berichtigt zu werden und in der Geburtsurkunde wurde ebenfalls eine Änderung der Eintragung vorgenommen. ${ }^{110}$

Auch Vornamensänderungen von Transvestiten kamen in der Praxis offenbar weiterhin vor. So führt Herrn einen Fall aus dem Jahr 1934 an, in dem ein Transvestit die Erlaubnis bekam, seinen Vornamen (in Toni) zu ändern und Frauenkleider zu tragen. Auch im vorhin aufgezeigten Fall Erna K. erfolgte im Dezember 1938 die Änderung des Vornamens auf Gerd. Gertrud W. hingegen wurde die Namensänderung 1940 verwehrt, wiewohl das Arbeitsamt den Antrag befürwortet hatte. Nach der Begründung des Amtes sei es nicht möglich, Gertrud W. „in Arbeit zu bringen“, weil „sie nach wie vor einen Mädchennamen führt und in Männerkleidung geht, woran sich jeder Arbeitgeber stößt."111

Franz von Schmidt berichtete 1960 überdies, allerdings ohne Quellenangabe, von zwei Fällen in Gladbeck 1940, in denen Frauen zu Männern erklärt wurden, wobei eines der „damals das

\footnotetext{
${ }^{108}$ RGBl 1938 I, S 9.

${ }^{109}$ Ministerial-Blatt des Reichs- und Preußischen Ministeriums des Innern 1938, 1345.

${ }^{110}$ MAßFELLNER, Führung 336.

${ }^{111}$ HerRn, Transvestitismus 358f.
}

Geschlecht wechselnden Mädchen“ sogar noch Marinesoldat geworden sei. ${ }^{112} 1943$ hatte sich außerdem Herrn zufolge ein Transvestit nach einer Haftstrafe wegen Wehrdienstentziehung die Geschlechtsteile entfernen lassen und die Vornamensänderung beantragt. ${ }^{113}$

\subsection{3. "Asozialität"}

Als Hintergrund für die zu behandelnden „Transvestitinnen“-Fälle ist auch die Frage zu thematisieren, ob bzw. inwieweit diese Gefahr liefen, als "Asoziale" eingestuft zu werden. Da der Transvestitismus nämlich von vielen Medizinern als "heilbar" mittels Psychologie, medizinischen Eingriffs (Kastration, Amputation) oder Hormonbehandlung angesehen wurde,,114 gab es auch Stimmen für eine Lagereinweisung als "Asoziale", wenngleich es für eine derartige Praxis keine Anhaltspunkte gibt. ${ }^{115}$ Für eine Einweisung sprach sich der Hamburger Mediziner Hermann F. Voss aus, ${ }^{116}$ da sich die Lage der Transvestiten nun „nach der Machtergreifung durch den Nationalsozialismus [...] geklärt" habe: „Mußten sie, wenn sie wegen ihrer Neigungen meist mit dem Aergenisparagraphen in Konflikt gekommen waren, nach Abbüßung ihrer Strafen früher immer wieder auf freien Fuß gesetzt werden, so erscheint das heute nicht immer notwendig. Früher konnte sich die Gesellschaft nicht schützen, da sie die Betreffenden nicht einwandfrei als für minder zurechnungsfähig und als unbedingt anstaltsbedürftig erklären konnten. Heute jedoch bietet sich die Möglichkeit, die Betreffenden eventuell in Sicherungsverwahrung zu nehmen oder auch eventuell zu kastrieren oder durch zeitweise,entsprechende Internierung' sie so $\mathrm{zu}$ beeindrucken, daß sie es vorziehen, ihre Neigung zu-

\footnotetext{
112 SCHMIDT, Nachtseiten 231.

${ }^{113}$ HeRRN, Schnittmuster 161.

114 Voss, Beitrag 41.

115 Siehe etwa SCHIKORRA, Kontinuitäten $128 \mathrm{ff}$.

116 Voss, Beitrag 44.
} 
rückzustellen. Thre asoziale Haltung, häufig gepaart mit kriminellen Handlungen rechtfertigt drakonische Maßnahmen seitens des Staates". Die „praktischen Erfahrungen der letzten Jahre“ hätten Erfolg gezeigt. Der Transvestitismus sei "weniger auffällig geworden“ und die "gefürchteten Maßnahmen, besonders die ,Internierung “" hätten Transvestiten veranlasst, ihren Neigungen nicht mehr öffentlich nachzugehen. Voss listete auch Daten zur Verbreitung des Transvestitismus in der Zwischenkriegszeit auf der Grundlage einer Anfrage bei den Polizeibehörden einiger deutscher Großstädte vor 1938 auf, die von nur sehr wenigen Fällen in den vorausgegangen 15 Jahren zeugen. Das von Voss untersuchte Hamburger Material von 61 der Polizei näher bekannten Fällen ging von 13 Prozent weiblichen Transvestiten aus, wobei seines Erachtens „die Lesbierinnen meistens keine vollständige Umkleidung vollziehen und kaum oder gar nicht auffallen", weshalb sie nicht als Transvestitinnen geführt würden. ${ }^{117}$

\section{3. Österreich in der Zwischenkriegs- zeit und unter der NS-Herrschaft}

\subsubsection{Transvestitismus}

Wie Herrn zur Frage des Tragens von Kleidern des Gegengeschlechts ausführt, liegen über ,juristische Regelungen außerhalb Deutschlands keine systematischen Angaben vor", für die Schweiz weist er aber ebenfalls behördliche Genehmigungen für das Tragen von Frauenkleidern seit 1920 nach. ${ }^{118}$ Für Österreich gab es jedoch „weder eine Preußen vergleichbare allgemeine noch der Schweiz analoge individuelle Regelung “. ${ }^{119}$ Dennoch wurden in Österreich in Einzelfällen bereits vor der Jahrhundertwende polizeiliche Bewilligungen zum Tragen von Männerkleidern ausgestellt. So besaß etwa Pepi

\footnotetext{
117 Ebd. 14f, 16.

118 Für Dänemark 1931 eine Vornamensänderung, HERRN, Schnittmuster 140.

119 Ebd.
}

Schmer, ursprünglich Tänzerin und Ballettmeisterin, als "Volkssänger Josefine Schmer" in den 1870er-Jahren eine polizeiliche Bewilligung für ihre Auftritte in Männerkleidung. ${ }^{120}$ Hermine Gartner trug ebenfalls Männerkleidung, verwendete als Malerin (und zwar religiöser Motive und Porträts) zum Zweck eines „freieren Fortkommens" den Künstlernamen Antonius Hermann, und lebte später an der italienischen Riviera als Mann. ${ }^{121}$

Polizeilich strafbar war jedenfalls seit der Kodifizierung des Verwaltungsstrafrechts $1925^{122}$ in diesem Kontext nur, wer „durch ein Verhalten, das Ärgernis zu erregen geeignet ist, die Ordnung an öffentlichen Orten stört, oder wer den öffentlichen Anstand verletzt. “123 Das Verhalten musste also „objektiv begründet sein", zur Strafbarkeit wegen öffentlicher Ruhestörung reichte nicht die Tatsache allein, dass „ein einzelner Ärgernis genommen und dies dann zur Störung der öffentlichen Ordnung geführt" hatte, sondern das Verhalten musste, um strafbar zu sein, „objektiv geeignet sein, Ärgernis zu erregen, und weiters im einzelnen Fall tatsächlich solches Ärgernis erregt und dadurch zur Störung der öffentlichen Ordnung geführt haben“. Die Verletzung des öffentlichen Anstandes war "dagegen an sich und ohne Rücksicht auf ein hervorgerufenes Ärgernis strafbar". ${ }^{124}$

Überliefert ist jedenfalls, dass im Sommer 1927 mehrere Wienerinnen an Polizei und Magistrat in Wien Gesuche stellten, auf Dauer Männerkleider tragen zu dürfen, was aber mit der Begründung abgelehnt wurde, dass nicht bewilligt werden könne, was nicht verboten sei. ${ }^{125}$ Diese Erklärung schaffte es sogar Anfang September 1927 auf die Titelseite der deutschen „Freun-

\footnotetext{
${ }^{120}$ HACKER, Ordnung 199.

${ }^{121}$ Ebd. 199f.

122 BARFUß, Verrechtlichung 219.

${ }^{123}$ Art. VII, Abs. 1 lit. a EGVG, BGBl. 273/1925.

${ }^{124}$ ARBESSER, LOEBELL, Verwaltungsstrafgesetz 24.

${ }^{125}$ PALKOW, MARCHAND, Liebeslexikon 942.
} 
din“, der vom „Bund für Menschenrecht“ von 1924 bis 1933 herausgegebenen Wochenschrift. Sie berichtete unter der Überschrift „Die Wienerinnen dürfen Männerkleidung tragen!“, dass einer Gruppe von Frauen, die bei der Wiener Polizei um die Bewilligung zum Tragen von Männerkleidern angesucht hatte, die Auskunft erteilt wurde, es gäbe keine verwaltungsrechtliche Vorschrift, welche die "Geschlechtsflucht in der Kleidung" pönalisiere, weshalb auch eine Ausnahmebewilligung nicht erforderlich sei.126 Nur wenn eine Frau also in Männerkleidern „die öffentliche Ordnung und Sittlichkeit verletzt", würde die Polizei gegen sie einschreiten, „nicht wegen des an sich nicht verbotenen Tragens von Männerkleidern". ${ }^{127}$

\subsubsection{Vornamensänderung und Personenstandsänderung}

Was die Frage der Namensänderung anbelangt, so galt in Österreich vor dem "Anschluss" 1938 das Hofkanzleidekret vom 5. Juni 1826,128 das zunächst nur die Änderung von „Geschlechtsnahmen“ und „beym Uebertritte zur christlichen Religion" auch von Vornamen ermöglichte. Mit Entscheidung des Verwaltungsgerichtshofs 1899 wurde aber klar gestellt, dass darüber hinaus „in besonders rücksichtswürdigen Fällen“ eine Änderung des Vornamens bewilligt werden könne, ein Rechtsanspruch bestand allerdings nicht. ${ }^{129}$ Die Entscheidung betreffend nichtadelige Personen lag seit 1866 bei der Landesstelle und erfolgte nach freiem Ermessen. ${ }^{130}$ Als Ände-

\footnotetext{
${ }^{126}$ Was die „Freundin“ plaudert. Die Wienerinnen dürfen Männerkleidung tragen! Was nicht verboten ist, ist erlaubt. - Eine Entscheidung der Wiener Polizei, in: Freundin 3. Jahrgang, Nr. 17 vom 5. 9. 1927, zit. n. ebd.

127 PALKOW, MARCHAND, Liebeslexikon 942; vgl. auch Polzer, Sexuellperverse 39.

${ }^{128}$ Hofkanzley-Decret vom 5. 6. 1826 betreffend die Beschränkung der Änderung der Geschlechtsnamen, PGS 54 (1826), Nr. 36, 56.

${ }^{129}$ ADLER, Namen 45, 54.

130 BERGER, Erwerb 123.
}

rung des Vornamens galt jede Änderung desselben, auch seine Abkürzung oder die Hinzufügung eines weiteren Vornamens. ${ }^{131}$

Die Familien- und Vornamen von KatholikInnen waren in Österreich von den (infolge des Konzils von Trient 1563 die Tauf- und Trauungsmatriken führenden) Pfarrern seit 1784 im staatlichen Auftrag in das sog. Geburtenbuch einzutragen. ${ }^{132}$ In weiterer Folge wurden auch die anderen gesetzlich anerkannten Kirchen und Religionsgemeinschaften zu einer derartigen staatlich normierten und kontrollierten Matrikenführung ermächtigt und ab 1868 überdies behördliche Zivilmatriken aufgrund der Ehegesetzgebung der Jahre 1868/1870 („Notzivilehe“) geführt. ${ }^{133}$ Eine Änderung des Eintrags in der Geburtsmatrik konnte nur „,auf Befehl der Landesstelle" erfolgen. ${ }^{134}$ Im Juli 1938 wurde die Geltung des deutschen Personenstandsgesetzes von 1937135 auf Österreich erstreckt,136 wodurch die Kompetenz zur Matrikenführung und damit auch die Eintragung einer Vornamensänderung mit 1. Jänner 1939 auf das Standesamt überging. Mit der Verordnung vom 24. Jänner 1939137 über die Einführung von namensrechtlichen Vorschriften im Lande Österreich und in den sudetendeutschen Gebieten wurde sodann der Geltungsbereich des Gesetzes über die Änderung von Familiennamen und Vornamen vom 5. Jänner 1938 sowie der beiden Verordnungen zur Durchführung des Gesetzes auch auf Österreich erstreckt. ${ }^{138}$

\footnotetext{
${ }^{131}$ ADLER, Namen 55.

132 Patent vom 20. 2. 1784, vgl. etwa BEIMROHR, Matriken 5-34.

133 NIEDERSTÄTtER, Matrikenführung 190f.

${ }^{134}$ ADLER, Namen 55.

${ }^{135}$ RGB1 1937 I, S $1146 f f$.

${ }^{136}$ RGBl 1938 I, S 803, vgl. SEIDL, Standesbeamte $193 f$.

137 RGBl 1939 I, S 81.

138 Ausf. Reiter-ZatlouKal, ,Entschleierung' (iE).
} 


\subsubsection{Weibliche Homosexualität}

Da - wie gezeigt - TransvestitInnen unter dem Generalverdacht der Homosexualität standen, soll hier ebenfalls kurz die einschlägige Rechtslage skizziert werden, um zu zeigen, dass für Transvestitinnen in Österreich der Versuch eines Geschlechtsrollenwechsels nur dann nicht riskant und möglicherweise erfolgversprechend war, wenn gegen sie keinerlei derartige Verdachtsmomente bestanden, da in Österreich weibliche Homosexualität kriminalgerichtlich strafbar war. In Preußen hingegen war dieser Straftatbestand bereits 1851 und schließlich im Deutschen Reich mit dem Reichsstrafgesetz 1871 gefallen, ${ }^{139}$ was dazu beitrug, dass sich für weibliche Homosexuelle in den 1920er und frühen 1930er-Jahren viele Freiräume auftaten und in den Großstädten eine vielfältige Subkultur entstand. ${ }^{140}$ In Österreich hingegen blieb nicht nur die „Szene“ vergleichsweise deutlich zurück, ${ }^{141}$ sondern auch das Strafgesetz von 1852 nach dem "Anschluss" 1938 weiterhin in Kraft, was dazu führte, dass deutsche Lesbierinnen entsprechend dem österreichischen Tatort verurteilt wurden, obwohl dieselbe Handlung im Deutschen Reich straflos war. ${ }^{142}$

Das StG 1852 bedrohte die „Unzucht wider die Natur mit Personen desselben Geschlechts" (§ 129 Abs. 1 StG) ${ }^{143}$ mit Kerkerstrafen von einem bis fünf Jahren, auch der Versuch war strafbar. Die strafbare Handlung war vom Gesetz allerdings nicht näher umschrieben, weshalb der Tatbestand von der Judikatur zunächst auf „,beischlafsähnliche Handlungen" eingeschränkt worden war. 1902 fiel diese Schranke, weil der-

\footnotetext{
139 SCHOPPMANN, Verhältnisse 128.

140 Siehe etwa SCHADER, Virile.

${ }^{141} \mathrm{Vgl}$. zur lesbischen Subkultur in Wien HaCKER, Tödlich, humorvoll; HACKER, Ordnung 349ff; in den Akten ist dies allerdings nicht greifbar, so MüLLER, FLECK, Unzucht wider die Natur 400-422.

${ }^{142}$ MÜLLER, FLECK, Unzucht wider die Natur 420.

143 Ebd. 419.
}

artige Handlungen bei Frauen „kaum denkbar" erschienen, und in weiterer Folge weitete der Oberste Gerichtshof 1906 den Unzuchtsbegriff dahingehend aus, dass darunter ,jeder der Erregung der Sinnenlust dienende, die Grenzen der Sitte und des Anstandes überschreitende geschlechtliche Mißbrauch des Körpers einer anderen Person zu verstehen" war, wenngleich seit einem OGH-Judikat von 1908 zur Erfüllung des Tatbestandes eine „masturbatorische Absicht“ vorliegen musste. ${ }^{144}$ Allerdings wurde in weiterer Folge die 1940 vom Reichsgericht vorgenommene Auslegung des Begriffs der „Unzucht wider die Natur" gemäß $§ 175$ RStGB auch in Österreich für §129-Praxis übernommen. Danach wurde nun nicht mehr auf „beischlafsähnliche und onanistische Handlungen“ abgestellt, sondern nun konnte „auch jede auf die Erregung oder Befriedigung der eigenen oder fremden Geschlechtslust gerichtete Handlung, die geeignet ist, das allgemeine Scham- und Sittlichkeitsgefühl in geschlechtlicher Hinsicht zu verletzen", den Tatbestand erfüllen. ${ }^{145}$

Allerdings fielen nicht nur die Strafen gegen lesbische Frauen „wesentlich milder" als jene gegen männliche Homosexuelle aus, sondern die Verfolgung von Frauen war auch in quantitativer Hinsicht deutlich niedriger als die der Männer, wenngleich die Polizei Wahl zufolge „aktiv nach Lesben suchte“. ${ }^{146}$ Nach Angaben des Wiener Strafrechtlers Roland Grassberger wurden in Österreich zwischen 1922 und 1937152 Frauen wegen gleichgeschlechtlicher Unzucht verurteilt, was durchschnittlich 9,5 Personen pro Jahr entspricht. In Wien, auf das ein Drittel aller österreichischen Verurteilungen entfiel, machten die Verurteilungen von Frauen in den Jahren 1924 bis 1936 3,5 Prozent aus und stiegen in den Jahren von 1938 bis 1943 auf 5,4 Prozent. ${ }^{147}$ Diese

\footnotetext{
144 SCHOPPMANN, Verhältnisse $126 f$.

${ }^{145}$ Vgl. ebd. 75, 136.

${ }^{146}$ WAHL Verfolgung 69.

147 SCHOPpMAnN, Sexualpolitik 47, 132, $140 \mathrm{f}$.
} 
niedrige Verurteilungsrate hat seinen Grund insbesondere darin, dass weibliche sexuelle Devianz generell als „sozial ungefährlicher" eingestuft wurde, was etwa auch darin seinen Niederschlag fand, dass die polizeiliche Meldepflicht für die „Polizeiliche Kriminalstatistik für das Deutsch“ im Bereich der „widernatürlichen Unzucht“ auf „Fälle mit Personen männlichen Geschlechts" beschränkt war. ${ }^{148}$ Überdies war weibliche Homosexualität weniger in der Öffentlichkeit sichtbar als männliche, die u.a. in Bädern, Saunen und Toiletten praktiziert wurde. Insgesamt kam es freilich auch in der "Ostmark“ zu einer Polarisierung der Geschlechterrollen, was sich u.a. in der härteren Bestrafung der „verführenden“ lesbischen Frau zeigt, die damit "gegen die Norm weiblicher Passivität" vorstoßen hatte. ${ }^{149}$

Angesichts der Strafbarkeit der weiblichen Homosexualität in Österreich wurde eine diesbezügliche Angleichung der deutschen Rechtlage übrigens schon vor dem "Anschluss" gefordert, ${ }^{150}$ und zwar wegen der durch die weibliche Homosexualität „,hervorgerufene[n] Umkehrung des natürlichen Empfindens der Frau, ihre dadurch verursachte Entfremdung von ihrer natürlichen Bestimmung als Gattin und Mutter und die wiederum dadurch bedingte Verfälschung und Schädigung des völkischen Lebens“.151 Homosexualität sollte "unerbittlich" bekämpft werden, denn sie bedeute „eine Entartung $[\ldots]$, eine Verweichlichung des Mannes und eine Vermännlichung der Frau“, wodurch sie die "gesunde Haltung des Volkes und damit seine Zukunft gefährde. Daher müsse „ein rück-

\footnotetext{
${ }^{148}$ Dienstvorschrift über die Führung der Polizeilichen Kriminalstatistik für das Deutsche Reich, Verlautbarung der Kriminalpolizeileistelle Wien vom 8. Dezember 1938, Beilage zum Meldeblatt der Kriminalpolizeileitstelle Wien 1 (1938) Nr. 123 (8. 12. 1938).

149 SCHOPPMANN, Verhältnisse 146.

150 SCHOPPMANN, Sexualpolitik 95-109.

${ }^{151}$ KLARE, Homosexualität und Strafrecht, zit. n. SCHOPPMANN, Verhältnisse 131.
}

sichtsloser Kampf gegen alle Entartungserscheinungen“ geführt werden. ${ }^{152}$ Durch „den homosexuellen Verkehr der Frauen“ würde außerdem, so der im Deutschen Reich tätige österreichische Strafrechtsprofessor Wenzel Gleispach, „auch ein vergiftender Einfluß auf die öffentliche Sexualmoral ausgeübt". Der Staat habe aber ein "großes Interesse“ an einem „normalen" Geschlechtsverkehr, der nicht durch „Perversitäten" beeinträchtigst werden solle. ${ }^{153}$ Sogar die Verfechter einer Ausdehnung der Strafbarkeit konzedierten allerdings, dass „die weibliche Homosexualität [...] kein politisches Problem darstellt, wie es bei der männlichen der Fall ist" ${ }^{\prime 154}$ Die Mehrheit der NS-Forscher sah lesbische Frauen überhaupt als die NS-Bevölkerungspolitik nicht gefährdende "Pseudo-Homosexuelle", die auch deshalb "sozial ungefährlich" seien, weil sie keine heterosexuellen Frauen „verführten". 155

Lesbischen Frauen blieb während des „Dritten Reiches" daher das Schicksal der homosexuellen Männer weitgehend erspart,156 wenn sie nicht Jüdinnen und/oder „Asoziale“ waren oder wegen Regimegegnerschaft verfolgt wurden. ${ }^{157}$ Eine systematische Verfolgung wie bei homosexuellen Männern fand bei lesbischen Frauen nicht statt, 158 was seinen Grund wohl in den Ansichten der Nationalsozialisten über die weibliche Sexualität generell findet. So ging man nicht nur von einer grundsätzlichen sexuellen Passivität der Frauen aus, sondern sprach eben auch von weiblicher "Pseudohomosexualität"

\footnotetext{
152 TetzlafF, Homosexualität und Jugend 6, zit. n. ebd. 132.

${ }^{153}$ Bericht über die 45. Sitzung der Strafrechtskommission am 18. 9. 1934, zit. n. SCHOPPMANN, Sexualpolitik 90.

${ }^{154}$ KlaRe, Homosexualität 137, zit. n. SCHOPPMANN, Zeit der Maskierung 19.

155 SCHOPPMANN, Nationalsozialismus $219 \mathrm{f}$.

${ }^{156}$ HAUER, Lesben 49.

157 SCHOPPMANN, Zeit der Maskierung 21ff.

158 Ebd. 24.
} 
und deren Kurierbarkeit. So meinte 1933 der Philosoph Ernst Bergmann, man müsse das „Geschlecht der Mannweiber [...] zwangsweise [...] begatten, um sie zu kurieren", sonst liefe man Gefahr, dass deren „Entartung“ vererbt werden könne. ${ }^{159}$ Auch in der Strafrechtskommission des Justizministeriums herrschte die Ansicht vor, dass bei homosexuellen Männern die "Zeugungskraft vergeudet" werde, da sie "zumeist aus der Fortpflanzung aus(scheiden)“, während das bei Frauen „nicht oder zumindest nicht im gleichen Maß der Fall“" sei. ${ }^{160}$ Nach Ansicht des Leiters der „Reichszentrale zur Bekämpfung der Homosexualität“ war jedenfalls bei der „lesbischen Liebe [...] die Gefahr für den Bestand des Volkes absolut nicht so groß wie bei den Homosexuellen", die er explizit als "Staatsfeinde" bezeichnete. Der größte Teil der lesbischen Frauen sei "alles andere als anormal veranlagt", es spielten vielmehr der „Mangel an männlichem Bekanntenkreis" ebenso eine Rolle wie eine „strenge Erziehung“. Erhielten sie „Gelegenheit, der ihnen von der Natur bestimmten Aufgabe nachzukommen", so würden sie „bestimmt nicht versagen". ${ }^{61}$ Auch war nach Ansicht des Reichsjustizministers die "gleichgeschlechtliche Betätigung zwischen Frauen [...] - abgesehen von Dirnenkreisen - nicht so verbreitet wie bei Männern“ und entziehe sich überdies „,angesichts der inneren Umgangsformen des gesellschaftlichen Verkehrs zwischen Frauen mehr der Beobachtung der Öffentlichkeit". Die damit verbundene größere Schwierigkeit der Feststel-

\footnotetext{
${ }^{159}$ BERGMANN, Erkenntnisgeist 404; auch MAIWALD, MisCHLER, Sexualität 185; SCHOPPMANN, Sexualpolitik 22.

${ }^{160}$ GÜRTNER, Kommendes deutsches Strafrecht 126, zit. n. SCHOPPMANN, Zeit der Maskierung 17; ScHOPPMANN, Sexualpolitik 23.

${ }^{161}$ Vortrag des Leiters der Reichszentrale Kriminalrat Meisinger, gehalten auf der Dienstversammlung der Medizinalderzernenten und -referenten am 5./6. 4. 1937 in Berlin, zit. n. GRAU, Homosexualität 153; SCHOPPMANN, Sexualpolitik 192.
}

lung solcher Handlungen würde die "Gefahr unberechtigter Anzeigen und Untersuchungen in sich tragen". „Der wichtige Grund für die Strafbarkeit der Unzucht zwischen Männern, der in der Verfälschung des öffentlichen Lebens durch die Schaffung von persönlichen Abhängigkeitsverhältnissen liegt, trifft bei Frauen", so der Reichsjustizminister, „wegen ihrer weniger maßgebenden Stellung in staatlichen und öffentlichen Ämtern nicht zu. Endlich sind auch Frauen, die sich einem widernatürlichen Verkehr hingeben, nicht in dem Maße wie homosexuelle Männer für immer als Zeugungsfaktoren verloren, da sie sich erfahrungsgemäß oft später wieder einem normalen Verkehr zuwenden. “162

Nach dem "Anschluss" bestand in Österreich für die Verfolgung u.a. der Homosexualität und überhaupt „sittenwidrigen Verhaltens" zunächst die Zuständigkeit der Gestapo (Staatspolizeileitstelle Wien, Referat II S). Mit April 1939 wurden allerdings diejenigen einschlägigen Anzeigen, in die keine „rassisch" oder politisch belasteten Personen sowie keine Angehörigen der NSDAP oder ihrer Gliederungen verwickelt waren, der Kriminalpolizeileitstelle Wien abgetreten, ab September 1939 grundsätzlich alle neu angezeigten Fälle. ${ }^{163}$

\footnotetext{
${ }^{162}$ Der Reichsminister der Justiz an den Reichkommissar für die besetzten norwegischen Gebiete in Oslo, 18. 6. 1942, zit. n. GRAU, Homosexualität 114.

${ }^{163}$ Das Referat II S wurde in ein Sachgebiet mit der Bezeichnung II H/S des Referates II H umgewandelt, das die noch nicht abgeschlossenen Fälle bis zum Jahresende 1940 weiter bearbeitete, vgl. dazu WEISS, Geheime Staatspolizei 451. Wie das von Andreas Brunner und Hannes Sulzenbacher am QWIEN aktuell betriebene Projekt „Namentliche Erfassung der homosexuellen und transgender Opfer des Nationalsozialismus in Wien" allerdings zeigt, verblieben nicht nur einige Fälle bei der Gestapo, sondern wurden von dieser auch - aus welchen Gründen auch immer - neu begonnen.
} 


\section{Der Fall Mathilde/ Mathias Robert S.}

Der Fall der 1899 in Wien geborenen und heimatberechtigten Mathilde Maria („Maro“) S. ${ }^{164}$ begann bereits im Oktober 1936, als sie nach der Übersiedlung von Wien nach Niederösterreich bei der Bezirkshauptmannschaft St. Pölten einen Antrag auf Vornamensänderung auf Matthias Robert einbrachte. ${ }^{165}$ Nach dem (im Niederösterreichischen Landesarchiv befindlichen, aber nicht vollständigen) Akt äußerte sich die niederösterreichische Landessanitätsdirektion in diesem Fall dahingehend, dass der Antragstellerin bei einer Operation „ein myomatös entarteter Uterus mit allerdings fraglichen Anhängen entfernt" worden war, womit aber "nicht gesagt" sei, „dass das weibliche Geschlecht des Gesuchstellers über allen Zweifel erhaben" sei. Es könne sich bei den entfernten Anhängen" nämlich auch um eine „männliche Geschlechtsdrüse gehandelt haben oder es können solche Drüsen oder Drüsenreste noch im Körper zurückgeblieben sein." Jedenfalls sei nicht ausgeschlossen, "dass es sich im gegebenen Falle auch um eine Zwitterbildung handeln“ könne. Dafür sprach nach Ansicht der Landessanitätsdirektion, dass es „,bei der praktisch vollkommen durch Operation kastrierten Frau nach dem Eingriffe [...] zu keinerlei Ausfallserscheinungen gekommen" sei, was bei einer 37-jährigen Frau „eigentlich unvermeidlich wäre“. Die „Feststellung ob Mann oder Frau oder Zwitter" sei aber für das Ansuchen um Vornamensänderung "sicher von untergeordneter Bedeutung". Bei diesem „Individuum“ werde man jedenfalls ,in Zukunft mit keinerlei unliebsamen Überraschungen mehr zu rechnen haben“, sie sei als Frau „zur Empfängnis völlig ungeeignet, als Mann zur Zeugung

\footnotetext{
${ }^{164}$ Ich danke Stefan Eminger, NöLA, für den Hinweis auf diesen Fall.

165 Siehe zum Folgenden NöLA, Landesamt I/8, Gruppe 8, Zl. 12.515/1939, Kt. 245.
}

ebenso“. Für eine militärische Dienstleistung käme sie „nach Alter und Konstitution nicht mehr in Frage“. Also seien „wesentlich mehr die von der Gesuchstellerin ziemlich glaubwürdig geschilderten Konflikte zu beachten, denen sie sowohl durch die Umwelt als auch seelisch ausgesetzt ist, ferner die Unmöglichkeit sich im Leben durchsetzen zu können, wenn sie dauernd gezwungen wird sich als Frau zu gehaben, wiewohl sie in der Kleidung als Frau ständig Gegenstand missliebigen Auffallens ist." Schließlich sei "dabei auch nicht ausseracht zu lassen, dass durch die stets gegebenen Konflikte beachtenswerte gesundheitliche Störungen auftreten müssen, die letzten Endes zur völligen Arbeitsunfähigkeit führen müssen“. Nach Ansicht der Landessanitätsdirektion könne daher "dem Ansuchen willfahrt werden".

Während also die Landessanitätsdirektion mit den beruflichen sowie sonstigen lebensweltlichen Problemen der Antragstellerin sowie den zu erwartenden gesundheitlichen Schäden argumentierte, ähnlich wie in Deutschland zuvor die Gutachten Hirschfelds, und sich für einen juristischen Geschlechtswechsel aussprach, zog sich die Landeshauptmannschaft auf ein offenbar negatives, dem Akt aber nicht einliegendes amtsärztliches Gutachten zurück: Die Antragstellerin fühle sich zwar „zugehörig zum männlichen Geschlecht", habe aber ein zuvor eingebrachtes „Ansuchen um entsprechende Berichtigung der Matrik [...] zurückgezogen" und damit zugegeben, "dass der Nachweis, sie gehöre dem männlichen Typus zu, nicht erbracht werden kann“. In diesem Fall würden nämlich „die äusseren Geschlechtsteile deutlich, wie aus den ärztlichen Gutachten einwandfrei hervorgeht, den weiblichen Typus aufweisen“, weshalb „die erforderliche Rücksichtswürdigkeit für die Bewilligung der Namensänderung nicht gegeben" sei. Mit Bezug auf das Ergebnis der amtsärztlichen Untersuchung liege also kein Grund vor, "die untersuchte Person als männlich zu bezeichnen, da sie das Bild einer körperlich voll- 
kommen normal gebauten Frau zeigt". Es dürfe "daher nicht angehen, einer Person, welche selbst bei genauer ärztl[icher] Untersuchung als Frau bezeichnet wird, einen männlichen Vornamen zu bewilligen“. Das „letzte Kriterium, ob die Keimdrüsen als männl[lich] oder weiblich zu bezeichnen sind", sei allerdings infolge der seinerzeitigen Operation „nicht feststellbar." Hinsichtlich der Empfehlung der Landessanitätsdirektion betonte die Landeshauptmannschaft, dass ohnehin gemäß den „heutigen Gepflogenheiten das Tragen von männl[lichen] Kleidern seitens Frauen oft genug vorkommt, insbes. am Land und in Kur- und Badeorten, und keinerlei polizeiliche Vorschrift dem entgegensteht."

Dem Antrag auf Vornamensänderung wurde daher 1937 mangels „Rücksichtswürdigkeit" nicht stattgegeben. Da ihr die „Führung männlicher Vornamen nicht bewilligt werden" könne, habe Mathilde Maria S. folglich fortan weiterhin „weibliche Vornamen zu führen“. Dagegen erhob die Antragstellerin im September 1937 Berufung und führte als Begründung an, dass die ihr bei der Übergabe des Bescheides ausgehändigten Personaldokumente "polizeilicherseits als unglaubwürdig beanständet" worden und daher für sie "als Ausweispapiere unbrauchbar" seien.

Am 4. März 1938 stellte Mathilde Maria S. in weiterer Folge bei der Landeshauptmannschaft den Antrag auf „schriftliche polizeiliche Bewilligung zum Tragen männlicher Kleidung" - wiewohl dies nach österreichischem Recht nach wie vor nicht erforderlich war - und auf „Eintragung des Schriftstellernamens Mathias Robert $\mathrm{S}[\ldots]$ in seinen [sic] Pass oder in eine polizeiliche Legitimation". 166 Überdies ersuchte sie, darum, "gütigst dafür Vorsorge treffen zu wollen", dass sie etwaige Zuschriften in dieser Angelegenheit "unter Maro" oder „ohne jegliche Anrede“, kei-

166 Siehe zum Folgenden NöLA, Landeshauptmannschaft NÖ, Landesamt I/6a, Gruppe XVII, Zl. 374/938, Kt. 103. nesfalls aber unter „Fräulein“ zugesendet erhalte, könne doch eine solche Anschrift „zufolge des kleinen Ortes“, in dem sie derzeit lebe, „neuerdings unliebsames Aufsehen hervorrufen und die hart erkämpfte Ruhe [...ihrer] äusseren Existenz abermals schwer erschüttern".

Zur Begründung ihres Antrages führte die Antragstellerin an, dass sie "als zweitgeborenes Zwillingsgeschwister eines gesunden, normalen Knaben [...] mit 1,45 kg scheintot zur Welt gekommen“ sei und bei der Nottaufe „nach kurzen Zweifeln" an ihrer Geschlechtszugehörigkeit den Namen Mathilde erhalten habe. Die Eltern hätten sie zwar als Mädchen aufgezogen, aber schon von früher Kindheit an sei „eine Divergenz zwischen der körperlich weiblichen Entwicklung und der seelisch-geistig männlichen Wesensart auffällig" gewesen, was aber in der Erziehung "keinerlei Unterstützung" gefunden habe. Trotz ihrer "oft verzweifeltsten Anstrengungen“", zu begreifen, welche Art des Verhaltens von ihr erwartet werde und sich danach zu richten, sei diese „Divergenz mit den Jahren immer größer" geworden, zumal mit zunehmendem Alter "eine stets augenfälligere Männlichkeit des Aussehens, der Gesichtszüge, Halsund Nackenpartien, Sprechweise, Stimme, Gang" hinzugetreten sei. Sie habe dann nach einer „aus den angegebenen Gründen reichlich konfliktreichen Absolvierung der Mittelschule“ auch während ihrer weiteren Studien (Malerei und Bildhauerei an Kunstschulen sowie Philosophie an der Universität) „keine soziale Einreihung" gefunden. Infolge der unentwegt erregten "Auffälligkeit" und „Sonderstellung" sei sie „zuinnerst bezügl[ich ... ihrer] Umweltbeziehungen rat- und hoffnungslos geworden" und habe ihren "lebhaften Sinn für Kameradschaft und den gemeinen Dienst am Ganzen zurückstellen müssen“. Daher habe sie sich „zu jenem Einzelgänger" entwickelt, der sie auch „im weiteren Leben" geblieben sei. Durch Krankheit und „zufolge des eigenen instinktiven Gefühles, bzw. der eigenen völligen Unvorstellbarkeit, 
[... sich] jemals als ,Frau' im Leben einreihen zu können“, habe sie auch ,jedes Bemühen, einen akad[emischen] Grad oder sonst die Voraussetzung zu einer Stellung im öffentl[ichen] Leben $\mathrm{zu}$ erlangen, von vornherein [als] völlig zwecklos" erachtet. Im Zuge ihres Erwerbslebens als Journalistin sei sie 1923, als sie nach eigenen Angaben noch langes Haar getragen habe, vom Direktor eines Zeitschriftenverlags sogar explizit gefragt worden, ob sie Hermaphrodit sei. 1924 habe sie ein Zeitungsredakteur aufgrund eines eingereichten Artikels überdies des Plagiats verdächtigt, „weil diese Arbeit, unmöglich von einer Frau' geschrieben sein könne“. Jedes „persönliche Auftreten“ sei mit „verletzende[r] Neugier intimer Natur" verbunden gewesen, ${ }^{167}$ und das ",erstaunte Interesse“, das ihre Person immer erwecke, habe ihre "definitive Aufnahme in eine Arbeitsgemeinschaft durch die Schwierigkeit, [... sich] anderen präsentieren zu können" und damit ein „Weiterkommen im Erwerbsleben [...] nahezu unmöglich“" gemacht.168 Auch „die private, gesellschaftl[iche] Einreihung" sei auf die "gleichen Schwierigkeiten" gestoßen. Sie schilderte die sie verstörenden Reaktionen der MitbürgerInnen bei verschiedenen Gelegenheiten, wie einem Ballbesuch, ${ }^{169}$ der Aufnahme in einen

\footnotetext{
167 Zur Illustration führte sie an, dass sogar die Hausgehilfin ihrer Eltern die Mutter gefragt habe, warum „der junge Herr sich weibl[ich] trage und Fräulein genannt" werde.

${ }^{168}$ Bei einer Schauspieler-Aufnahmeprüfung habe sie solange keine Probleme gehabt, solange sie einen Mantel anhatte, als sie diesen ablegen musste und „in einem weibl[ichen] Kleid dastand, erscholl von dem auf den Galerien anwesenden Publikum ein tosendes Gelächter" und sie habe „raschest abziehen“ müssen. 169 Sie habe 1923 "nach jahrelangem Widerstreben“ und von ihren Eltern "dringend gebeten", „wenigstens einmal einen Ball zu besuchen", dies tatsächlich getan, wobei dieses Unterfangen damit geendet habe, das der ihr bislang unbekannte "Comitéherr" die „sicherlich dezent vorgebrachte, aber tief bestürzte Frage" gestellt habe: ,Junger Freund, wie kommen sie in diese Kleidung?" Weiters sei bei ihrem Antreten zur Neulingsprüfung beim Florettfechten, als sie den
}

Fechtkurs, beim Ausfüllen des Meldezettels u. dgl. wobei mit zunehmendem Alter derartige Erlebnisse „,immer häufiger und krasser" geworden seien. So habe man es ihr ab der zweiten Hälfte der 1920er Jahre unmöglich gemacht, „,allein ein öffentl[iches] Schwimmbad aufzusuchen“, weil ihr „bereits am Schalter die Lösung einer Damenkabine zufolge des Verdachtes, [... sich] aus unlauteren Gründen den Eintritt in diese Abteilung verschaffen zu wollen, verweigert wurde“. Auch ein öffentliches Frauen-WC habe sie wegen der großen "Entrüstung“ einer „erregten Menschenansammlung" nicht betreten können. ${ }^{170}$ Als sie 1930 am Wiener Rathaus ihren Heimatschein behob, habe sie den Beamten „nur mit Mühe überzeugen" können, dass sie nicht ihr Zwillingsbruder sei. Überdies sei sie 1930 nachts in Wien von zwei Polizisten aufgehalten und um "die Berechtigung, weibl[iche] Kleidung zu tragen", gefragt worden - was freilich insofern erstaunt, als es eine solche nach den wenigen vorliegenden Berichten eigentlich nicht gab. Eine „längere Unterredung“ mit den Polizisten habe trotz ihrer Bemühungen „erst recht wieder mit dem Eindruck der Polizeiorgane (geendet), es mit einem Mann in Weiberkleidern zu

Damen-Umkleideraum betreten wollte, ein „entsetztes Geschrei“ der darin befindlichen Damen entstanden und ihr ein "separater Umkleideraum zugewiesen" worden. Auch habe sich eine Dame geweigert, mit ihr anzutreten, weil sie nach der Prüfungsordnung nicht verpflichtet sei, „mit einem Mann zu fechten". Bei einer Vorsprache am Zollamt habe man sie, obwohl sie ohne Mantel in einem Kleid erschienen war, „konsequent als ,Herr' angesprochen“. In einem Berghotel, in dem sie im Schianzug erschien, sei die Angabe des weiblichen Geschlechts bei der Anmeldung „als ein grossartiger Witz mit homerischem Gelächter quittiert" worden. Kinder hätten sie überdies „mit seltsamer Hartnäckigkeit" trotz weiblicher Kleidung "Onkel“ genannt.

170 Sie habe ungefähr 1929 einmal ein WC in der Stadtbahnhaltestelle Stadtpark aufsuchen wollen, woraufhin sie "mindestens 15 Minuten unflätig beschimpft" worden sei, bis sie „endlich den Ort verlassen und fluchtartig entweichen konnte." 
tun zu haben“. Als Konsequenz daraus habe sie über Jahre hinweg „vor jedem herannahenden Polizisten einen weiten Bogen gemacht" und sie sei wiederholt "rasch auf fahrende Strassenbahnen aufgesprungen, um einer Ansprache durch Wachleute zu entgehen“. Die Jahre bis 1936, als sie sich endgültig entschloss, „,nur mehr männliche Kleidung zu tragen“, seien daher "zum reinsten Spiessrutenlaufen" geworden. Nach ihrer Übersiedlung nach Niederösterreich sei sie anlässlich eines Besuches in Wien bei Vorweisung ihres Passes von der Polizei "abermals aufs schwerste der Dokumentenfälschung verdächtigt" worden, weil man ihr ",angegebenes weib1 [iches] Geschlecht" nicht glaubte. Nach „mühevoller Auseinandersetzung" habe sie die Polizei „mit der strengsten Weisung, um Korrektur [... ihrer] Dokumente, bzw. um Ausstellung glaubwürdiger Ausweispapiere behördlich anzusuchen, entlassen“. Die "schweren seelischen Einwirkungen und damit die Beeinträchtigung der Arbeitskraft dürften begreiflich sein“, resümierte Mathilde S.

Sie habe daher bei der zuständigen Behörde St. Pölten im Oktober 1936 das Gesuch um Dokumentenänderung bzw. Änderung des Vornamens Mathilde in Mathias Robert eingebracht, und zwar "entsprechend [... ihrem] gleichlautenden Schriftstellernamen und anklingend an [... ihren] allgemeinen Rufnamen "Maro'." Dieses Gesuch sei aber zum Zeitpunkt der Einbringung des gegenständlichen Antrages noch unentschieden, weil im Berufungsstadium. Zur "augenblicklichen Situation" gab Mathilde S. an, dass sie "ausschließlich männliche Kleidung trage, niemals und nirgends den geringsten Anstand gehabt oder irgend ein Aufsehen erregt habe". Sogar die Bevölkerung ihres derzeitigen Wohnortes, die sie „von früher Kindheit“ kenne, habe die Änderung „überraschend schnell akzeptiert". Sie werde "ausnahmslos von jedem, auch von der hiesig. Gendarmerie als ,Herr $S[\ldots]^{\prime}$ angesprochen". Nie mehr könne sie sich entschließen, „wieder weibl[iche] Kleidung zu tragen und so die „Hölle, die [... sie] durchschritten habe, wiederum auf [... sich] zu nehmen.“ Aufgrund der „abermaligen ,Ungesetzlichkeit' [... ihres] Zustandes" sei sie aber in ihrem Erwerbsleben „weitgehend lahmgelegt", da sie „keine behördl[iche] Berechtigung zu [... ihrem] Auftreten nachweisen" bzw. sich nicht dementsprechend ausweisen könne und daher "gegen jede etwaige böswillige Denunziation unguter Elemente rechtlich schutz- und wehrlos" sei.

Verbunden war der Antrag auf schriftliche Erlaubnis zum Tragen männlicher Kleidung und damit die Bewilligung, sich mit ihrem Rufnamen Maro (eventuell Maro Mathilde) oder mit ihrem Schriftstellernamen Mathias Robert S. nennen und melden zu dürfen, mit einer eidesstaatlichen Erklärung der Antragstellerin, die erbetene Bewilligung "zu keinem wie immer gearteten unlauteren oder ungesetzlichen Zwecke" anzustreben. Darüber hinaus betonte Mathilde S. explizit, weder "homosexuell noch im üblichen Wortsinn Transvestit“ zu sein, „,sofern man unter letzterem einen Menschen mit besonderer Neigung zum Tragen der Kleidung des anderen Geschlechtes versteht". Sie habe „keine besondere ,Liebe' zur männlichen Kleidung“, vielmehr betrachte sie die Kleidungsfrage an sich „stets ziemlich gleichgültig [...] und unwesentlich“. Um den impliziten Homosexualitätsvorwurf zu zerstreuen, betonte Mathilde S., dass ihrerseits Frauen gegenüber "gerade zufolge [... ihres] weibl[lichen] Körpers eine unerbittliche Schranke" bestehe, die ihr eine sexuelle Beziehung zu einer anderen Frau "unmöglich" mache. Dem „Typus der ,homosex[uellen] Frau' “ sei sie daher "seit jeher fremd gegenüber gestanden“. Die „mannigfachen Annäherungsversuche von Frauen", denen sie, als sie noch weibliche Kleidung getragen habe, „von früh an ausgesetzt" gewesen sei, hätten sie "stets peinlich berührt und gequält". Sie empfinde es "als eine große Wohltat", dass ihre männliche Kleidung „auf Frauen als eine deutliche Schranke zu wir- 
ken scheint, derzufolge sie sich [...ihr] nicht mehr so ohne weiters zu nähern wagen“. Dass ihr „die Natur jede sex[uelle] Partnerschaft verwehrt" habe, sei ihr außerdem "vollkommen klar".

Als Ende Juni 1938 die Berufung gegen den ablehnenden erstinstanzlichen Bescheid betreffend die Bewilligung zur Führung eines männlichen Vornamens noch immer nicht entschieden und der zweite Antrag infolgedessen auch nicht weiterbearbeitet wurde, setzte sich Mathilde S. daraufhin offenbar mit dem Institut für gerichtliche Medizin in Wien in Verbindung. Ein Aktenvermerk hielt nämlich Anfang August 1938 fest, dass sich laut den Angaben der Antragstellerin Anton Werkgartner, der seit 1928 außerordentlicher Professor für gerichtliche Medizin, seit 1936 Mitglied der NSDAP und nach dem "Anschluss" 1938 kommissarischer Leiter des Wiener Gerichtsmedizinischen Instituts war, 171 bereit erklärt habe, kostenlos ein Gutachten abzugeben. Deshalb sei der Akt dem Gerichtsmedizinischen Institut zu übersenden, ${ }^{172}$ was wenige Tage später auch „,behufs allfälliger Äußerung“ geschah. Als Mathilde S. dann persönlich bei der Behörde vorsprach, wurde „ihm“ laut Amtsvermerk „bedeutet", dass die Erledigung des zweiten Antrages entfalle, wenn er die Bewilligung zur Führung eines männlichen Vornamens erhalte, da eine Rücksprache mit dem für das Matrikenwesen zuständigen Landesamt ergeben habe, dass über die Berufung auf Grund eines beizubringenden gerichtsmedizinischen Gutach-

\footnotetext{
1711939 wechselte Werkgartner auf eine planmäßige außerordentliche Professur nach Graz. Daneben war er Richter am Erbgesundheitsgericht und seit 1940 am Erbgesundheitsobergericht für die Steiermark und Kärnten, vgl. HERBER, Gerichtsmedizin 12.

172 NöLA, Landesamt I/8, Gruppe 8, Zl. 12.515/1939, Kt. 245.
}

tens im eigenen Wirkungsbereich entschieden würde. ${ }^{173}$

Mitte November 1938 teilte das Gemeindeamt St. Veit an der Gölsen der Landeshauptmannschaft mit, dass „der bisher als ,Mathilde S[... ] gemeldete Einwohner sich mit heutigem Tage h.a. als Mathias Robert S[...] umgemeldet" und dabei „auf einen bei der Landeshauptmannschaft Niederdonau laufenden Akt und die zufolge polizeilicher Beanstandung schon vor zwei Jahren erfolgte restlose Einziehung sämtlicher auf den Vornamen ,Mathilde' lautenden Personaldokumente" verwiesen habe. Der Gemeindeverwalter ersuchte um Weisungen, „ob diese Ummeldung zur Kenntnis genommen werden“ könne. Die Landeshauptmannschaft beantwortete diese Anfrage dahingehend, dass die Ummeldung „unter dem Vorbehalt vorläufig zur Kenntnis genommen werden" könne, dass der Genannte nach Durchführung der im Zuge befindlichen Änderung seines bisherigen weiblichen Vornamens in einen männlichen Vornamen die auf den Namen Mathias Robert lautenden Personaldokumente vorzuweisen in der Lage sein wird."

Nachdem offenbar das gerichtsmedizinische Gutachten, das aber nicht im Akt aufliegt und bislang auch nicht aufgefunden werden konnte, ${ }^{174}$ bei der Landeshauptmannschaft eingegangen war, stellte das Gesundheitsamt Ende August 1939 „,neuerlich den Antrag, das Ansuchen des Maro S[...] zu bewilligen und ihn nun entgiltig dem männlichen Geschlechte zuzurechnen". Bereits drei Tage später informierte die Landeshauptmannschaft Niederdonau die "Verwaltung der Stadt Wien", dass der Gesuchsteller „auf Grund des beiliegenden Gutachtens

\footnotetext{
${ }^{173}$ Dazu und zum Folgenden NöLA, Landeshauptmannschaft NÖ, Landesamt I/6a, Gruppe XVII, Zl. 374/938, Kt. 103.

${ }^{174}$ In den vom Wiener Gerichtsmedizinischen Institut dem ÖStA übergebenen Beständen befindet es sich nach Auskunft von Susanne Fröhlich jedenfalls nicht.
} 
des Prof. Dr. Werkgartner dem männlichen Geschlechte angehört", weshalb „um entsprechende Berichtigung der Geburtsmatrik ersucht" wurde. ${ }^{175}$ Diese erfolgte dann auch in der zuständigen Wiener Pfarrgemeinde, in dem sowohl der Vorname als auch das Geschlecht geändert wurden. ${ }^{176}$

1940 heiratete Mathias Robert S. und nahm 1943 mit seiner Ehefrau ein im Jahr davor geborenes Mädchen als Ziehtochter an, das er einige Jahre nach Kriegsende auch adoptierte. ${ }^{177}$ Er verstarb im November 1982. ${ }^{178}$

\section{Der Fall Emma/Rudolf Emil K.}

Der Fall der Emma K., der sich abschriftlich im Wiener Stadt- und Landesarchiv als „Musterakt" befindet, 179 begann damit, dass Anfang Dezember 1938 die "Transvestitin“180 und Photographengehilfin Emma K., geboren 1894 in Wien

${ }^{175}$ NöLA, Landesamt I/8, Gruppe 8, Zl. 12.515/1939, Kt. 245.

${ }^{176}$ Geburts- und Taufbuch der Pfarre St. Rochus und St. Sebastian Tom. 71/90/271; Dank an Eva Maria Haas, Pfarrkanzlei St. Rochus und St. Sebastian, und Andreas Lotz, Matrikenamt der Erzdiözese Wien, für die Unterstützung bei der Informationsbeschaffung.

177 Ebd.: Eheschließung „1t. Mitteilung des Standesamtes St. Pölten unter Fam Buch Nr. 626/40“ (Eintrag bestätigt durch das Standesamt St. Pölten; Dank an Cornelia Huber).

${ }^{178}$ So die Meldedaten und der Eintrag im Sterbebuch. Für diese Informationen danke ich Helmut Praschl, Abteilung Melde- und Bauamt der Marktgemeinde St. Veit an der Gölsen.

179 Akt Emma K., Vornamensänderung in Emil Rudolf (Abschrift), Musterakt mit grundsätzlicher Entscheidung des Reichsministers des Inneren, Der Polizeipräsident in Wien, II-8010-40, WStLA, M.Abt. 116, Namensänderung, Normalien A 40/2, Kt. 3. Der Originalakt konnte bislang nicht aufgefunden werden. Herzlich gedankt sei Michaela Laichmann, WStLA, und Stefan Eminger, NöLA, für ihre diesbezüglichen Bemühungen.

${ }^{180}$ So explizit ÖStA, BKA-I II/6, Zl. 2.685/1939, Sig. $8 / 2$ c. und wohnhaft in St. Pölten „in Männerkleidern“ in der Kriminalpolizeileitstelle Wien erschien, ${ }^{181}$ der die Polizeidirektion St. Pölten unterstand. ${ }^{182}$ Dort gab sie, wie der „Dauerdienst" der Kripoleitstelle in einer Niederschrift festhielt, an, dass sie seit ihrem 26. Lebensjahr Männerkleider trage, und zwar "teils aus Veranlagung, teils um des leichteren Fortkommens willen", und sich deshalb auch als Mann mit dem Namen Rudolf K. polizeilich gemeldet habe. ${ }^{183}$ Dass Emma K. nicht nur auf ihre "Veranlagung" verwies, sondern auf das „leichtere Fortkommen“ als Mann kann möglicher Weise einerseits auf die Kenntnis der reichsdeutschen Praxis zurückzuführen sein. Andererseits zeigen auch die überlieferten österreichischen Fälle weiblichen Passings zwischen 1870 und 1938, dass diesem „in starkem Maße“ die „Sehnsucht nach bzw. der Zwang zu

${ }^{181}$ Die Kripoleitstelle Wien, deren Akten offenbar nicht erhalten sind, war nach der Eingliederung der Kriminalpolizei des Landes Österreich in die deutsche Kriminalpolizei durch Erlass des Reichsführers SS und Chefs der Deutschen Polizei vom 25. 3. 1938 aus der Kriminalpolizei Wien hervorgegangen und fungierte auch gleichzeitig als Kriminalpolizeistelle für Wien und Niederösterreich. Sie war unter der amtlichen Bezeichnung „Staatliche Kriminalpolizei - Kriminalpolizeileitstelle Wien“ "zuständig und verantwortlich für die Durchführung aller kriminalpolizeilichen Aufgaben im Rahmen der bestehenden reichsdeutschen kriminalpolizeilichen Erlasse“. Im Besonderen hatte sie die Verbindung des dem Reichssicherheitshauptamtes eingegliederten Reichskriminalpolizeiamts mit den Kriminalpolizeistellen aufrechtzuerhalten sowie die kriminalpolizeilichen Vorgänge zentral zu erfassen und auszuwerten, WETZ, Geschichte 104. Außerdem wurden Kriminalpolizeistellen in Linz, Salzburg, Innsbruck, Klagenfurt, Graz und Eisenstadt errichtet, vgl. Runderlass des Reichsführers SS und Chef der Deutschen Polizei vom 25. 3. 1938 bzw. Verlautbarung des Chefs der Kriminalpolizeileitstelle Wien, Meldeblatt der Kriminalpolizeistelle Wien 1 (1938), Nr. 1 (4.4.1938), 1; Nr. 2 (6. 4. 1938), 7; 1 (59), Nr. 59 (25. 6. 1938), Beilage.

182 Übersicht über das Zuständigkeitsgebiet der Kriminalpolizeileitstelle Wien, Meldeblatt der Kriminalpolizeileitstelle Wien 1 (1938), Nr. 24 (9. 5. 1938) 61. ${ }^{183}$ Musterakt Emma K. 
der Erlangung von Verdienstmöglichkeiten überhaupt oder von ,besseren'/ individuell bevorzugten Berufschancen bei mittellosen und Unterschichtfrauen" als Motiv zugrunde lag. ${ }^{184}$ Was die Frage ihrer "Veranlagung" anbelangt, so führte Emma K. aus, dass darunter hinsichtlich ihrer Person zu verstehen sei, dass sie sich „in Frauenkleidern nicht wohl fühle" und „,auch in erotischer Hinsicht nicht wie eine Frau empfinde". ${ }^{\prime 85}$

Als Grund ihrer Vorsprache gab sie an, dass sie Ende November eine Aufforderung des Wehrbezirkskommandos erhalten habe, sich „zur Untersuchung“ einzufinden. Da sie aber in St. Pölten jedermann kenne, habe sie sich "gescheut", dieser Aufforderung nachzukommen und stelle sich der Polizeibehörde, der sie alle ihre Dokumente lautend auf den Namen Rudolf K. vorlegte. Sie gab weiters an, ihre Eltern nie gekannt und bei Zieheltern aufgewachsen zu sein, wobei der Ziehvater bereits gestorben sei, die Ziehmutter bei ihr wohne und von ihr erhalten werde. ${ }^{186}$ Um eine „Bewilligung zum Tragen von Männerkleidern" habe sie nicht angesucht, sie sei unbescholten und stehe in Arbeit, nämlich als „Heimretoucheur" für verschiedene Fotoateliers. ${ }^{187}$

Bereits am nächsten Tag ordnete die Polizeidirektion Wien an, dass Emma K. "geschlechtlich zu untersuchen" sei. Der umgehend erstattete polizeiärztliche Befund vom Dezember 1938 vermerkte kurz und bündig: „Kleiner, gedrungener Körperbau, der in Hosen tatsächlich die Gestalt eines Mannes vortäuscht. Das Genital ist vollkommen weiblich, auch die Schambehaarung trägt weiblichen Typus. $\mathrm{Zu}$ erwähnen ist, daß die Frau bereits als kleines Kind ihren Puppen

\footnotetext{
${ }^{184}$ HACKER, Ordnung 201.

${ }^{185}$ Musterakt Emma K.

${ }^{186}$ Es war damals freilich nicht unüblich, dass ,,alleinstehende" Frauen nicht allein, sondern sehr häufig bei den Eltern lebten, vgl. etwa URBAN, Wohnungsfrage; auch HACKER, Ordnung 414.

${ }^{187}$ Dazu und zum Folgenden: Musterakt Emma K.
}

die Haare abgeschnitten hat, und sie in Hosen gesteckt hat. In Frauenkleidern wurde sie oftmals für einen Mann gehalten. Sexuell steht sie beiden Geschlechtern ziemlich gleichgültig gegenüber. Sie menstruiert normal."

Die Kriminalpolizeileitstelle Wien trat danach den Akt „zur Kenntnisnahme und ev. weiteren Veranlassung" an die Polizeidirektion St. Pölten $a b,{ }^{188}$ da "durch die ärztliche Untersuchung ihr weibl[iches] Geschlecht festgestellt wurde". ${ }^{189}$ Der Polizeidirektor in St. Pölten hielt sodann in einem Aktenvermerk fest, dass Emma K., die im hiesigen Meldekataster unter dem Namen Rudolf K. gemeldet war, vorgeladen wurde und angab, dass sie sich unter dem Namen ihres Bruders Rudolf gemeldet und dessen Personaldaten auch bei der polizeilichen Meldung angegeben habe. Der Meldekataster wurde nun auf Grund des vorgelegten Taufscheins von Emma K. richtiggestellt, der Akt zur „weiteren Veranlassung“ an die Kriminalabteilung abgetreten, welche nicht nur die Verständigung des Wehrbezirkskommandos übernahm, sondern auch den Akt an das Amtsgericht „zur Kenntnisnahme und eventuellen weiteren Strafamtshandlung" gegen Emma K. wegen Falschmeldung übermittelte.

Ende Dezember vermerkte der Polizeidirektor in St. Pölten darüber hinaus, ${ }^{190}$ dass Emma K. nicht Mitglied der NSDAP war, seit Ende November 1920 ununterbrochen in St. Pölten wohnte ${ }^{191}$ und noch nie einen Anlass $\mathrm{zu}$ einem polizeilichen

\footnotetext{
188 Die Archivbestände der Polizeidirektion St. Pölten, die sich nach wie vor als "Beuteakten“ in Moskau befinden (RGVA F. 1506), enthalten leider keine einschlägigen Akten. Auch die Findbücher zum Bestand Reichsministerium des Inneren lieferten ebenso wenig Hinweise wie eine Überprüfung der Kartothek des RGVA. Dank an Julia Köstenberger für die Recherche. 189 Dazu und zum Folgenden: Musterakt Emma K. ${ }^{190}$ Ebd.

${ }^{191}$ Nach dem Meldezettel vom 23. 11. 1919 war Emma K. noch wohnhaft Wien, ihre zuständige Heimatgemeinde war Neuhofen an der Ybbs (NÖ), vgl. WStLA, Meldewesen, D-Antiquariat.
} 
Einschreiten gegeben habe. Frauenkleider habe sie seit 1920 nicht mehr getragen, die Dokumente ihres seit 1920 verschollenen Bruders Rudolf ${ }^{192}$ von ihrer Mutter erhalten. In einem Bericht an die Kripoleitstelle Wien Ende Jänner 1939 wies er darauf hin, dass Emma K. beabsichtige, „um die Bewilligung zum Tragen der Männerkleidung anzusuchen". Sie trage "auch heute noch Männerkleidung“ und würde „,allgemein für einen Mann gehalten“. ${ }^{193}$

Tatsächlich wurde der Antrag auf Bewilligung des Tragens von Männerkleidung und Namensänderung von Emma K., vertreten durch einen St. Pöltener Rechtsanwalt, nur zwei Tage später an den Polizeidirektor in St. Pölten gestellt. ${ }^{194}$ In diesem führte sie u.a. aus, dass sich schon während ihrer Kindheit in ihrem "Gehaben ein starker bubenhafter Einschlag" gezeigt habe, da sie der Aufsicht der Zieheltern häufig "entwischt" sei sowie mit Knaben gespielt und sich gebalgt habe, während sie „Mädels aus dem Wege ging". Auch habe sie schon vor der Einschulung "einen starken Zug zur Knabenkleidung" gezeigt und sich solche, wo immer sie ihrer habhaft werden konnte, zugelegt. Die Zieheltern hätten sie "mehr wie einen Knaben heran(gezogen) auf die Jagd mit(genommen) und anderes mehr". Infolge von Nachstellungen des Ziehvaters ab dem elften Lebensjahr und der Eifersucht der Ziehmutter ${ }^{195}$ sei sie später in ein Pensionat gekommen, wo sie sich aber nicht wohlgefühlt habe und bei Besuchen des Ziehvaters auch nicht vor dessen Übergriffen geschützt war. Durch diese Nachstellungen des Ziehvaters habe sie jedenfalls ,jedes Gefühl für Männer verloren" - ein übrigens zeitgenössisch-ty-

192 Laut Meldezettel vom 31.3. 1920 war Rudolf K., Retoucheur, geb. 1898, bis 15.5.1920 wohnhaft in Wien, dann meldete er sich nach Leoben $a b$, seine Heimatgemeinde war ebenfalls Neuhofen an der Ybbs (NÖ), WStLA, Meldewesen, D-Antiquariat.

${ }^{193}$ Musterakt Emma K.

${ }^{194} \mathrm{Ebd}$.

195 Vgl. etwa DiENES, Transvestitismus 84. pisches „Anamnese“-Merkmal weiblicher Transvestiten und Transsexueller. ${ }^{196}$

Im Zuge ihres Heranwachsens habe sich dann in ihrem "ganzen Auftreten" gezeigt, dass sie "mehr männliche Eigenschaften" hatte und wiederholt sei behauptet worden, sie "sei ein Mann in Mädchenkleidung". Nach einem erneuten „Anschlag“ des Ziehvaters auf die nun 17-Jährige ließen sich den Angaben der Antragstellerin zufolge die Zieheltern scheiden. Die Ziehmutter, die durch die Scheidung alle erbrechtlichen Ansprüche gegen ihren Mann und durch die Inflation ihr Vermögen verloren hatte, lebe seither bei ihr. Dem Antrag zufolge hatte Emma K. „versucht, eine Stellung zu erhalten, war zuerst in einem Büro, lernte dann fotografieren und war dann auch in diesem Berufe tätig“. In dieser Zeit, etwa im Jahr 1920, habe sie gemerkt, dass sie sich „mit Männerkleidern [...] leichter durchsetzen" könne, ${ }^{197}$ seither Männerkleider getragen und sich „,auch tatsächlich bis zum heutigen Tage redlich durchgebracht". Sie erhalte ihre blinde Ziehmutter, benütze, um „leichter durchzukommen“, die Papiere ihres Bruders und lebe seither unter diesem Namen, auf den auch alle ihre Zeugnisse ausgestellt wurden. Erst bei der "Assentierung" sei ihr Geschlecht aufgefallen, was zur Einleitung eines Strafverfahrens gegen sie geführt habe, das zum Antragszeitpunkt aber bereits eingestellt worden sei. So lebe sie nun seit 20 Jahren "ohne jemanden zu schaden in Männerkleidung, übe rechtschaffen [... ihren] Beruf aus und werde von allen als Mann angesehen“. Käme „die Sache“ jedoch „in die Oeffentlichkeit", dann wäre sie „in St. Pölten für alle Male unmöglich gemacht und würde [... ihr] Brot, aber auch die Aussicht auf eine andere Stellung verlieren". Behielte sie aber ihr bisheriges Leben, fiele sie niemandem zur Last und

\footnotetext{
${ }^{196}$ Vgl. ebd. 55.

${ }^{197}$ Die besseren Chancen im Beruf waren ein oftmals angegebener Grund, die Geschlechterrolle zu wechseln, vgl. DIENES Transvestitismus 89f.
} 
könne die 80 Jahre alte Mutter weiter unterstützen. Daher stelle sie den Antrag, ihr das Tragen von Männerkleidern zu gestatten, die Namensänderung in Rudolf K. bewilligen $\mathrm{zu}$ wollen und unterzeichnete mit „Rudolf richtig Emma“ K. 198

Das von der Polizeidirektion St. Pölten eingeholte amtsärztliche "Zeugnis" befürwortete im April 1939 den Antrag, denn die polizeiärztliche Untersuchung der „Transvestitin“ Emma K. habe ergeben, dass die "seelische Abartigkeit" bereits auf die frühe Jugend zurückgehe, schon vor Schulbeginn der Verkleidungstrieb bestanden und sich beim Spiel mit Kindern sowie beim Puppenspiel gezeigt habe. Außerdem sei die Genannte "sehr an der eigenen Ziehmutter gehangen", 199 habe sich aus deren Kleidern "damals als Kind männliche Kleider improvisiert“. „Der ganze Ideenkomplex", so führte das amtsärztliche Gutachten aus, "hat schon damals einen erotischen Hintergrund gehabt", und auch "heute gilt, wenn überhaupt Interesse empfunden wird, dieses nur Frauen reifen Alters und vom Habitus der Ziehmutter". Im Allgemeinen würde aber von der Antragstellerin „erotisches Interesse als äußerst gering bezeichnet", habe nach eigener Aussage „nie zur Betätigung geführt” und würde auch „nur selten Masturbation betrieben, und zwar ohne irgendwelche Hilfsvorstellungen erotischen Inhalts." Außerdem bestehe, abgesehen von der „infantilen Erotik“, der „Wunsch, ein Mann zu sein oder als solcher zu gelten, um im Leben kräftiger zu sein und der bedürftigen Ziehmutter finanziell besser helfen zu können“, wobei diese „materiellen Erwägungen" seit 1920 mehr in den Vordergrund gerückt seien, und zwar „wegen der Aussicht, als Mann viel leichter als als Frau eine Stelle zu erhalten." Alles gehe „,auf frühe kindliche Vorstellungen

\footnotetext{
198 Dazu und zum Folgenden: Musterakt Emma K.

199 Nach DiEnES, Transvestitismus 69, stellt die Mutter in Fällen des weiblichen Transvestitismus bzw. der weiblichen Transsexualität in der Regel die dominante Bezugsperson dar.
}

zurück, die meist für das ganze Leben richtunggebend bleiben und vom ärztlichen Standpunkt in größtmöglicherweise entschuldigungswürdig" seien. Es folgte eine ausführliche Beschreibung der körperlichen Beschaffenheit der Antragstellerin, wobei das äußere Genital als „,vollkommen weiblich" bezeichnet und festgehalten wurde, dass von einer "inneren Untersuchung“ Abstand genommen werden musste, weil ein derartiger Versuch „Schmerzen, Angstzustände und starke Abwehr" ausgelöst habe. Da die Menstruation seit dem 12. Lebensjahr regelmäBig erfolgt sei, kam das amtsärztliche Zeugnis zum Ergebnis, dass also auch eine „normale weibliche Eierstocktätigkeit zu bestehen" scheine. Da eine Frau nach dem Verständnis der Medizin seit der Mitte des 19. Jahrhunderts nur wegen der Eierstöcke eine Frau war200 bzw. die Ovarien nach damaligem Verständnis als „Inbegriff der inneren Drüse“ und damit als der Ort galten, „wo das Weib im innersten Wesen ,Weib” ist", 201 kam auch das amtsärztliche Gutachten über das wahre Geschlecht von Mathilde S. zum Ergebnis: ${ }^{202}$ „Es liegt demnach weder äußeres noch inneres Zwittertum vor. Es handelt sich demnach im vorliegenden Falle um einen Verkleidungstrieb (Transvestitismus) auf Grunde einer psychologisch begründeten, bis in die frühe Kindheit zurückzuverfolgenden Veranlagung". „Wirtschaftliche Motive" hätten bei Emma K. „erst spät (seit ca. 1920) eine zusätzliche Rolle“ gespielt. Eine „Täuschungsabsicht als solche“ sei „in keiner Weise festzustellen“. In Frauenkleidung würde Emma K. „auf dem heutigen regen Arbeitsmarkt ebenfalls eine Beschäftigung finden, es ist aber vom ärztlichen Standpunkte vorauszusehen, daß bei der Veranlagung und der langen Gewöhnung an Männerkleidung ein

\footnotetext{
${ }^{200}$ Archille Chereau 1844: „Propter solum ovarium mulier erst quod id quod est", vgl. LAQUEUR, Leib 1992. ${ }^{201}$ LAHM, Ovarium 123, zit. n. SCHÄFFNER, Transformationen $287 \mathrm{f}$.

${ }^{202}$ Dazu und zum Folgenden Musterakt Emma K.
} 
Verkleidungsverbot eine schwere Störung auslösen kann, und muß in letzterem Fall mit einer schweren Erschütterung des seelischen Gleichgewichtes gerechnet werden". Emma K. wurde daher „vom ärztlichen Standpunkt größtmöglicher Berücksichtigung empfohlen."

In weiterer Folge wurde mit diesem Fall der Reichsführer SS befasst, ${ }^{203}$ dem Anfang Mai 1939 von der Kriminalpolizeileitstelle mitgeteilt wurde, dass es „dem Wunsche der Emma K[...] (entspricht), auch weiterhin Männerkleidung zu tragen". Über das Gesuch sei aber noch nicht entschieden worden, es würde vielmehr „mit der Entscheidung [...] zugewartet, bis in diesem Akte eine Genehmigung zur Bewilligung anher einlangt". Zur Genehmigung der damit ebenfalls angestrebten Namensänderung sei in Österreich "bisher die Landeshauptmannschaft zuständig". Was allfällige wirtschaftliche Nachteile der Gesuchstellerin im Falle einer Untersagung betreffe, so werde sie solche „im Falle der Untersagung des Tragens von Männerkleidern wohl nicht erleiden, doch wird diesbezüglich auf die Ausführungen im amtsärztlichen Zeugnis wegen der damit verbundenen schweren seelischen Störung hingewiesen." K. lebe jedenfalls „sehr bescheiden und zurückgezogen" und habe "bisher die Behörden noch nie zu Beanständungen veranlaßt". Es werde daher die Erteilung einer Genehmigung zum Tragen von Männerkleidung im Fall Emma K. polizeilich befürwortet.

In weiterer Folge beantragte auch das Reichskriminalpolizeiamt, ${ }^{204}$ Emma K. die Genehmigung

\footnotetext{
203 Nach Auskunft von Sabine Gresens, Bundesarchiv Berlin, existieren allerdings zum Fall Emma K. keine entsprechenden Unterlagen mehr, weder in den einschlägigen personenbezogenen Beständen, noch auch in den Akten des Reichsministeriums des Innern zu Namensänderungen.

${ }^{204}$ Das preußische Landeskriminalpolizeiamt wurde am 16.7.1937 in ein Reichskriminalpolizeiamt umgewandelt, das mit Bildung des Reichssicherheitshauptamtes am 27. 9. 1939 dessen Amt V bildete, vgl. WAGNER, Volksgemeinschaft 235.
}

zum Tragen von Männerkleidern zu erteilen. Mit Erlass vom 3. Juli $1939^{205}$ teilte schließlich der Reichsführer SS der Kriminalpolizeileitstelle Wien mit: „Ich bin einverstanden, daß der Emma K[...] in Anbetracht ihrer ärztlich festgestellten seelischen Abart die Genehmigung zum Tragen von Männerkleidung erteilt wird. Sie ist aber anzuhalten, keine öffentlichen Bedürfnisanstalten, Bäder und dergl. aufzusuchen, und darauf hinzuweisen, daß die Uebertretung dieses Verbotes den Widerruf der Genehmigung zur Folge habe. Wegen der notwendig werdenden Namensänderung ersuche ich das Weitere zu veranlassen“.206 Diesen Erlass übermittelte die Kriminalpolizeileitstelle Wien der Polizeidirektion in St. Pölten mit der Aufforderung zur „weiteren Amtshandlung". Daraufhin erging am 27. Juli 1939 ein Schreiben an Emma K. zuhanden ihres Rechtsanwalts, in dem die Entscheidung des Reichsführers betreffend die „Genehmigung zum Tragen von Männerkleidern" mitgeteilt wurde.

Am 5. August erging seitens des Polizeidirektors St. Pölten dann auch der Bescheid, mit dem Emma K. gestattet wurde, ihren Vornamen von Emma K. in Emil Rudolf K. zu ändern. Der Bescheid stützte sich laut Bescheidbegründung auf den Erlass des Reichsführers der SS vom 3. Juli 1939 und $\S 11$ des Gesetzes über die Änderung von Familien- und Vornamen vom 5. Jänner 1938, wonach ein Vorname bei Vorliegen eines wichtigen Grundes geändert werden durfte. Der Bescheid stellte nun im „Sinne des oben bezogenen Erlasses" fest, dass „die Wichtigkeit gegeben" sei. ${ }^{207}$ Umgehend übermittelte der Polizeidirektor in St. Pölten dem dortigen Oberbürgermeister eine Bescheidabschrift „zur Berichtigung

\footnotetext{
205 ÖStA, BKA-I II/6, Zl. 2.685/1939, Sig. 8/2c.

${ }^{206}$ Musterakt Emma K.

${ }^{207}$ Ebd.; auch Beilage der Karteikarte Stadtarchiv St. Pölten Emil Rudolf K.
} 
in den dortigen Amtsbehelfen“208 sowie dem Meldeamt.

Eine weitere Bescheidabschrift erging an die Landeshauptmannschaft Niederdonau, verbunden mit der "Bitte um Veranlassung der Matrikenberichtigung“. ${ }^{209}$ Diese fragte jedoch zurück: „Bestehen hinsichtlich des Geschlechtes der genannten Person irgendwelche Zweifel? Bejahendenfalls ist der Akt vorzulegen. Wieso hielt sich die dortige Behörde zur Fällung eines derartigen Bescheides für kompetent?" Der Polizeidirektor übermittelte der Landeshauptmannschaft nun den Vorakt, „obwohl hinsichtlich des Geschlechtes des Emil Rudolf K[...] keine Zweifel bestehen". Er wies darauf hin, dass die Fällung des Bescheides gemäß $\S 11$ des Gesetzes über die Änderung von Familiennamen und Vornamen vom 5. Jänner 1938 erfolgt sei, nach dem die Entscheidung über eine derartige Änderung der unteren Verwaltungsbehörde zustehe und sich die Genehmigung der Vornamensänderung "hauptsächlich“ auf das amtsärztliche Gutachten" sowie den Erlass des Reichsführers SS vom 3. Juli 1939 stütze.

Die Landeshauptmannschaft vertrat nun ihrerseits allerdings die Ansicht, dass eine Matrikenänderung nicht erfolgen könne: Mit dem Bescheid vom 5. August 1939 sei Emma K. die Namensänderung von Emma in Emil Rudolf auf Grund der Namensänderungsvorschriften erteilt worden, was auch zweifelsfrei eine polizeiliche Maßnahme darstelle. Laut ärztlicher Untersuchung sei jedoch "die Person weiblichen Geschlechtes" und würde "daher durch die Erlaubnis zum Tragen von Männerkleidern keineswegs juristisch zum Manne gestempelt". Sie könne daher "auch nicht ihren weiblichen Namen in einen männlichen mit der Wirkung, geändert' erhalten, dass ihr ,Personenstand' von nun an das Merkmal ,männliches Geschlecht ${ }^{\prime}$

\footnotetext{
${ }^{208}$ Musterakt Emma K.; auch Karteikarte Meldeamt Stadtarchiv St. Pölten Emil Rudolf K.

${ }^{209}$ Dazu und zum Folgenden: Musterakt Emma K.
}

erhält, da dies ja eine Irreführung der Behörden [und] der Öffentlichkeit bedeuten würde“. Die Erlaubnis, sich im Verkehr mit dritten Personen eines männlichen Vornamens bedienen zu dürfen, könne daher ebenso wie die Erlaubnis, Männerkleider tragen zu dürfen, „nur eine polizeiliche Massnahme darstellen“, nicht aber die Grundlage für eine Matrikenänderung und damit eine Änderung des Personenstandes bilden. Die Landeshauptmannschaft empfahl daher die Abänderung des Namensänderungsbescheids dahingehend, "dass auch die Bewilligung des Führens des Namens Emil Rudolf sich nur als polizeiliche Maßnahme darstellt, wobei die näheren Bedingungen, unter denen die Führung des Männernamens gestattet wird, dem dortigen Ermessen anheimgestellt" sei. Die „Anmerkung der Führung des Vornamens Emil Rudolf in die Geburtsmatrik" betrachtete die Landeshauptmannschaft daher als "gegenstandslos."

Der Polizeidirektor in St. Pölten vertrat allerdings die Ansicht, dass durch die mit „hiesigem Bescheid erfolgte Genehmigung der Vornamensänderung [...] der Partei ein bestimmtes Recht erwachsen“ sei. Durch die „Unterlassung der Änderung des Matrikenverzeichnisses" sei "eine Unterschiedlichkeit zwischen dem der Partei erwachsenen Recht und der öffentlich rechtlichen Verzeichnisse gegeben“. Er stellte daher Anfang Oktober „anheim, die amtswegige Behebung des von hier erlassenen Bescheides in die Wege zu leiten."

Die Landeshauptmannschaft legte nun den Akt dem Ministerium für innere und kulturelle Angelegenheiten des Landes Österreich mit der „Bitte um Kenntnisnahme und Erteilung einer allfälligen Weisung" vor, da es ihrer Ansicht nach „gänzlich ausgeschlossen“ sei, „einer Frauensperson einen männlichen Vornamen mit der Wirkung beizulegen, dass auch in den Matriken die Aenderung zu vermerken wäre“. Es könne sich "höchstens um eine polizeiliche Massnahme handeln, die einer Frauensperson, welche Männerkleider trägt, die Erlaubnis gibt, im täglichen 
Verkehr sich männlicher Vornamen zu bedienen". Die angeregte amtswegige Behebung des Bescheides des Polizeidirektors von St. Pölten erachtete die Landeshauptmannschaft für „unmöglich. ${ }^{210}$

Das Ministerium seinerseits legte diese Anfrage dem Reichsinnenministerium in Berlin „mit dem ergebenen Ersuchen um Entscheidung vor", da es sich im Hinblick auf die mit Erlass des Reichskommissars für die Wiedervereinigung Österreichs mit dem Deutschen Reich vom 4. Oktober 1939 verfügte Auflösung des Amtes des Reichsstatthalters und des Ministeriums für innere und kulturelle Angelegenheiten ${ }^{211}$ „zur Erteilung einer Weisung nicht mehr für zuständig" erachtete.

Am 26. Februar 1940 wies schließlich das Reichsinnenministerium den Landeshauptmann von Niederdonau in Wien an, die Namensänderung „auch in der Geburtsmatrik zu vermerken“. Zu Begründung wurde darauf verwiesen, dass „eine Vornamensänderung nach Maßgabe des Gesetzes über die Änderung von Familiennamen und Vornamen vom 5. Jänner 1938 vorliegt, nach der "die Transvestitin berechtigt" sei, den Vornamen Emil Rudolf zu tragen. „Die Auswirkungen dieser Namensänderung“ seien "die gleichen wie in jedem anderen Falle", weshalb auch in diesem Fall der Vermerk in der Geburtsmatrik vorzunehmen sei. ${ }^{212}$

Somit war im Fall der Emma K. einer biologisch eindeutig dem weiblichen Geschlecht zugewiesenen Person ohne jedweden operativen Eingriff aufgrund der festgestellten „seelischen Abartig-

${ }^{210}$ Dazu und zum Folgenden: ÖStA, BKA-I II/6, Zl. 2.685/1939, Sig. 8/2c.

${ }^{211}$ Infolge der Dritten Verordnung über die Übertragung von Aufgaben und Befugnissen des Reichsstatthalters (Österreichische Landesregierung) vom 16.9. 1939, RGB1 1939, I S 1845, die ihrerseits auf Grund der $\S \S 16$ und 18 des Gesetzes über den Aufbau der Verwaltung in der Ostmark (Ostmarkgesetz) vom 14.4. 1939, RGBl 1939 I, S 777, beruhte.

212 WStLA, Musterakt Emma K. keit" von den NS-Behörden der juristische Geschlechtswechsel gestattet worden. Hinweise auf eine polizeiliche Überwachung oder weitere behördliche Aktivitäten liegen nicht vor. ${ }^{213}$ Emma bzw. nun Emil Rudolf K., der seine Mutter bis zu ihrem Tod am 9. November 1945 weiterhin in seinem Haushalt betreute, ${ }^{214}$ starb am 20. August 1955 in St. Pölten.215 Der aktuellen Eigentümerin des von ihm bewohnten Hauses ist er als ",kleiner, rundlicher, freundlicher Herr" in Erinnerung geblieben. ${ }^{216}$

\section{Schlussbetrachtung}

Der Fall Mathilde/Mathias Robert S. ist nach der Aktenlage dem "Zwittertum“ oder „Hermaphroditismus" (bzw. "Pseudohermaphrodismus“) zuzurechnen, also nach Hirschfeld denjenigen Fällen, „in denen die Geschlechtsorgane selbst infolge einer zweigeschlechtlichen Entwicklung, beziehungsweise einer Hemmung der sexuellen Differenzierung mehr oder weniger ausgesprochene Mischungen beider Geschlechtstypen zeigen" (wobei er auch betont, dass die vier Grundtypen, zu denen auch die Homo- und Bisexualität sowie die Androgynie und Gynandrie zählen, „in jeder nur denkbaren Weise untereinander vermischt sein und gleichzeitig bei einem Individuum auftreten“ können). ${ }^{217}$

\footnotetext{
${ }^{213}$ Insbes. dürften keine weiteren Veranlassungen seitens der Militärbehörden gesetzt worden zu sein. Jedenfalls existieren nach dem aktuellen Recherchestand keine einschlägigen Akten - weder im Bundesarchiv Berlin, vgl. Anm. 203, noch auch in der Deutschen Dienststelle für die Benachrichtigung der nächsten Angehörigen von Gefallenen der ehemaligen Deutschen Wehrmacht, noch auch im ÖStA (Dank an Roman Eccher für diese Information).

${ }^{214}$ Karteikarte Meldeamt und Stadtarchiv St. Pölten Emma K., geb. W.

${ }^{215}$ Karteikarte Stadtarchiv St. Pölten Emil Rudolf K ${ }^{216}$ Ich danke Helmut Dorfner, Stadtarchiv St. Pölten, für die telefonische Recherche.

${ }^{217}$ HIRSCHFELD Umwandlungen 3.
} 
Allerdings war, wie gezeigt, die Beweislage für eine derartige Einstufung als Intersex-Person dürftig, und erst das nicht mehr auffindbare gerichtsmedizinische Gutachten brachte im Verfahren den Durchbruch. Da dieser Fall bereits vor Beginn der NS-Herrschaft, also zu einer Zeit seinen Anfang nahm, als Personenstandänderungen nur im Fall eines zweifelhaften Geschlechts bzw. einer irrigen Geschlechtszuordnung vorgenommen werden konnten, ist freilich nicht auszuschließen, dass es sich im Fall von Mathilde/Mathias Robert S. möglicherweise um einen weiteren Fall der Transsexualität handelte und von ihr/ihm nur deshalb mit "Zwittertum" argumentiert wurde, da dies eben in Österreich vor 1938 die einzige Möglichkeit darstellte, um eine derartige Vornamens- und Personenstandsänderung $\mathrm{zu}$ erreichen. Die juristische Geschlechtsumwandlung fand in diesem Fall jedenfalls, wie gezeigt, erst unter der NS-Herrschaft statt - wenngleich nach längerem Verfahren - und ähnelt durchaus dem eingangs angesprochenen reichsdeutschen Fall der Louise Sch. Der Fall Emma/Emil Rudolf K. stellt im Unterschied dazu einen eindeutigen Fall der Transsexualität dar, wobei die Anlegung eines „Musterakts“ als starkes Indiz dafür gewertet werden kann, dass die von Herrn aufgezeigte unterschiedliche Behandlung der von ihm beschriebenen Transsexuellenfälle Erna K. und Gertrud W. keineswegs auf eine Änderung der Praxis zwischen 1935 und 1940 schließen lässt. Relevant für die fortgesetzt tolerante Behandlung der TransvestitInnen bzw. Transsexuellen erscheint freilich auch weiterhin, wie der Fall Emma/Emil Rudolf K. zeigt, der „Ausschluss eines jeglichen Homosexualitätsverdachts“. ${ }^{218}$ Für den Befund Herrns allerdings, dass die InhaberInnen von „Transvestitenscheinen“ unter „starker staatlicher Repression und polizeilicher Kontrol-

\footnotetext{
${ }^{218}$ HERRN, Schnittmuster 165.
}

$\mathrm{le}^{\varkappa_{219}}$ standen, finden sich im Fall Emma K. keinerlei Hinweise. Nicht nur hatte sich die Polizei im Verfahren mit einem, doch eher wohlwollend oberflächlichen amtsärztlichen Gutachten begnügt, sondern es wurde auch von begleitender polizeilicher Kontrolle abgesehen.

Wahl zufolge fiel den Nationalsozialisten „nicht leicht“, mit Transsexuellen „umzugehen, ihre Verfolgungsmaßstäbe ließen sich auf diese Opfer nur schlecht anwenden“. Insofern seien „die Urteile und Verfolgungssituationen, die Transvestiten und Trandsgenders betreffen, auch recht unterschiedlich“.220 Da Wahl sich jedoch nur mit männlichen, durchwegs homosexuellen "Transvestiten" beschäftigte, ist seine These dahingehend zu modifizieren, dass angesichts des NS-Geschlechterbildes von einer grundsätzlich anderen Einschätzung und Behandlung männlicher und weiblicher Transvestiten ausgegangen werden muss. Sofern Passing Women nämlich offenbar in "sittlicher" Hinsicht polizeilich unbedenklich erschienen, konnten sie auch im Nationalsozialismus mit einer gewissen Toleranz rechnen, obwohl der "Transvestitismus" selbst in der NS-Ideologie klar als „,sexuelle Entartung“ bzw. „Perversität” klassifiziert wurde.

Einerseits hat diese nachsichtige Haltung wohl mit der grundsätzlich unterschiedlichen Bewertung weiblicher Sexualität und deren geringerer Sichtbarkeit zu tun. Andererseits könnte die von Geerte Maks für die Sexualwissenschaft vor dem Nationalsozialismus getroffene Beobachtung auch hier zutreffen, dass Männer selbst dann nach wie vor als Männer - wenngleich nun „entartete" - angesehen wurden, wenn sie Transvestiten und/oder Homosexuelle waren, während Frauen, „die aufgrund ihres Erscheinungsbildes, ihrer Lebensweise oder Sexualität als ,männlich galten, $[\ldots]$ ab einer bestimmten Grenze überhaupt nicht mehr als Frauen angesehen" wur-

\footnotetext{
${ }^{219}$ Ebd.; auch HulversCHEIDT, Rezension. ${ }^{220}$ WAHL, Verfolgung 71.
} 
den, „da sie ihrem Wesen nach als männlich galten". ${ }^{221}$ Für die Fortpflanzung standen sie ohnedies aus körperlichen und/oder seelischen Gründen nicht zur Verfügung - im Unterschied zu „bloßen“ Lesbierinnen.

Dazu kommt, dass Herrn zufolge die Transvestitinnen im Unterschied zu den homosexuellen Transvestiten, wenngleich "die meisten [...] sexuell Frauen begehrten, [...] weniger darauf bedacht gewesen zu sein" schienen, "durch die Männerkleidung Sexualpartnerinnen $\mathrm{zu}$ attrahieren“. Vielmehr versuchten die Passing women, eben „als Männer durchzugehen“ und diese umfassend „sozial zu verkörpern, sei es in partnerschaftlichen Beziehungen [...], sei es im privaten oder öffentlichen Alltagsleben“. ${ }^{222}$

Somit diente der Geschlechtswechsel letztlich auch einer Verfestigung der dominanten Geschlechterordnung, orientierte sich dieser doch grundsätzlich an der Geschlechterdichotomie und ihren Geschlechtsstereotypen, womit er ein drittes Geschlecht grundsätzlich ausschloss. Die Vermeidung eines geschlechtlichen Schwebezustandes führte allerdings zugleich zur Schaffung von "Männern" im juristischen Sinn, die nicht nur physiologisch überhaupt keine Männer oder zumindest keine "Vollmänner" waren, sondern damit auch nicht dem idealtypischen NSMännerbild entsprachen. Das Verhalten von Emma K. und Mathilde S. stellt sich so zwar als subversiv im Sinne einer Überschreitung der vom Patriarchat gezogenen Grenzen, ${ }^{223}$ andererseits aber gleichzeitig als affirmativ im Sinne der herrschenden Geschlechterdichotomie dar, wobei die Gründe für deren Geschlechtswechsel im subjektiv-psychologischen wie im wirtschaftlichen Bereich lagen.

Wiewohl auch im Nachkriegsdeutschland die Weimarer Praxis des "Transvestitenscheins"

\footnotetext{
${ }^{221}$ MAK, Passing Women 399.

222 HERRN, Transvestitismus 360.

${ }^{223}$ Vgl. HACKER, Ordnung 192.
}

und der Genehmigung eines geschlechtsneutralen Namens unvermindert fortgesetzt wurde, ${ }^{224}$ so ist doch befremdlich, dass gerade während des NS-Terrorregimes in Einzelfällen zugestanden wurde, was in den Nachkriegsgesellschaften in Deutschland und Österreich bis in die jüngste Vergangenheit grundsätzlich ausgeschlossen war, ${ }^{225}$ nämlich ein juristischer Geschlechtswechsel ohne medizinische geschlechtsanpassende Eingriffe, wiewohl solche bereits in der Zwischenkriegszeit möglich waren ${ }^{226}$ und auch unter der NS-Herrschaft in Einzelfällen vorgenommen wurden.227

In Deutschland hatte nämlich noch das Transsexuellengesetz von $1980^{228}$ einerseits eine sog. kleine Lösung vorgesehen, die es unter bestimmten Voraussetzungen erlaubte, den oder die Vornamen zu ändern, andererseits eine sog. große Lösung, bei der nicht nur der Vorname geändert, sondern auch die Eintragung im Personenstandsregister vorgenommen wurde. Die große Lösung setzte allerdings ursprünglich voraus, dass die Person, welche die Änderung beantragte, nicht verheiratet und "dauernd fortpflanzungsunfähig“ war sowie „sich einem ihre

${ }^{224}$ Siehe den Fall Toni (Anton) Simon (1887-1979), der nach dem Zweiten Weltkrieg von den deutschen Behörden die Erlaubnis bekommen hatte, sich öffentlich in Frauenkleidern zu bewegen und regelmäßig Pornos aus Dänemark nach Deutschland schmuggelte, vgl. WOLFERT, Skandinavien 236.

${ }^{225}$ Vgl. dazu und zur Lage in Europa etwa Council of Europe, Le transsexualisme.

${ }^{226}$ Wurden zunächst Penis und Hoden entfernt (so etwa 1922 im Fall Rudolf/Dorchen), so fand die erste vollständige Mann-zu-Frau Operation 1931 statt (Lili Elbe/Einar Wegener), vgl. dazu ausf. HERRN, Schnittmuster $167 \mathrm{ff}$.

227 Wenngleich für diese Zeit bislang nur der Fall eines männlichen Transsexuellen 1939/40 dokumentiert ist. 1934 war bereits die Vornamensänderung erfolgt, zur Personenstandskorrektur kam es allerdings erst 1948, vgl. HERRN, Transvestitismus 364.

${ }^{228}$ Gesetz über die Änderung der Vornamen und die Feststellung der Geschlechtszugehörigkeit in besonderen Fällen, BGBl. 1980 I S. 1654ff 
äußeren Geschlechtsmerkmale verändernden operativen Eingriff unterzogen hat, durch den eine deutliche Annäherung an das Erscheinungsbild des anderen Geschlechts erreicht worden ist". Erst 2011 fiel in Deutschland der Operationszwang weg, ${ }^{229}$ d.h. eine Frau oder ein Mann muss sich nicht mehr die Geschlechtsteile entfernen oder umformen lassen, um die personenstandsrechtliche Anerkennung im empfundenen Geschlecht zu erhalten. ${ }^{230}$

In Österreich war eine Änderung des Geschlechtseintrags aufgrund des Personenstandsgesetzes 1983 dann zulässig, wenn die Personenstandsbehörde eine Beurkundung zu ändern hatte, die seit der Eintragung „unrichtig“ geworden war, ${ }^{231}$ wobei zur Änderung des Personenstands eine Änderung des Geschlechtseintrags im Geburtenbuch durch das Standesamt des Geburtsortes erforderlich ist. Der Transsexuellen-Erlass $1983^{232}$ sah vor, dass nur im Fall der Durchführung operativer und begleitender sonstiger medizinischer Maßnahmen mit dem Ziel einer wenigstens äußerlichen Angleichung an das Gegengeschlecht eine Änderung des Geschlechts (gemäß dem Personenstandsgesetz) durch Eintragung eines Randvermerks im Geburtenbuch erfolgen konnte. 233 Nachdem 2006 der Verfassungsgerichtshof diesen Erlass aufgehoben hatte, ${ }^{234}$ schrieb sodann der Innenminister 2007 den Standesämtern in einer internen Weisung vor, Personenstandsänderungen nur dann zu genehmigen, wenn der/die AntragstellerIn

\footnotetext{
${ }^{229} \mathrm{http}: / /$ www.bundesverfassungsgericht.de/entschei dungen/rs20110111_1bvr329507.html (abgerufen am 29. 7. 2013).

${ }^{230}$ Vgl. PrantL, Geschlecht.

${ }^{231}$ BGB1. 60/1983.

232 http://www.transx.at/Lib/Law/BMI1983.pdf; http://www.transx.at/Dokumente/Erlass96.pdf (abgerufen am 29. 7. 2013).

${ }^{233}$ Dies überdies auch nur, wenn der Antragsteller oder die Antragstellerin nicht verheiratet war.

${ }^{234}$ http://www.transx.at/Dokumente/VGH_TSerla0606 .pdf (abgerufen am 29. 7. 2013).
}

„ein psychotherapeutisches Gutachten und den Befund der geschlechtsanpassenden Operation" vorlegte. ${ }^{235}$ Der Operationszwang wurde jedoch 2009 vom Verfassungsgerichtshof endgültig beseitigt, der feststellte, dass „Voraussetzung für die Änderung des Geschlechtseintrags im Geburtenbuch [...] keineswegs eine (genitalverändernde) Operation" sei. 236

Weitere Forschungsarbeiten zur Geschichte der "Transvestiten“ bzw. Transgender-Personen im Nationalsozialismus werden nötig sein, um mittels eines größeren Samples mehr Licht in dieses Phänomen zu bringen. Mit diesem Beitrag konnten allerdings die bisherigen Forschungen dahingehend ergänzt werden, dass „Transvestitenscheine" auch noch nach 1938 erteilt wurden,, 237 erging der Bescheid für Emma/Rudolf Emil K. doch am 5. August 1939, die Personenstandänderung erfolgte überhaupt erst 1940. Die Frage, ob der Kriegsbeginn also diesbezüglich einen Wandel in der NS-Sexual- und Geschlechterpolitik markiert, ${ }^{238}$ kann daher wohl verneint werden. Beide in diesem Beitrag präsentierten Fälle entstammen überdies nicht dem bisher primär untersuchten großstädtischen Milieu: Emma/Rudolf Emil K. lebte in St. Pölten,239 das 1939 mit 41.819 EinwohnerInnen bloß etwas größer als etwa der Wiener Bezirk Josefstadt war; Mathilde/Mathias Robert S. wohnte in einer kleinen niederösterreichischen Marktgemeinde mit überhaupt nur 3.695 EinwohnerInnen.240

235 http://www.transx.at/Dokumente/TS-

Erlass_BMI_2007.pdf (abgerufen am 29. 7. 2013).

${ }^{236}$ Erkenntnis des VfGH, 3.12.2009, GZ B1973/08, Slg. 18929. Im Mai 2010 hob schließlich das Innenministerium seine Erlässe auf und übertrug die Kompetenz für die Personenstandsänderung den Ländern, http://www.transx.at/Dokumente/BMI_11052010.pdf (abgerufen am 29. 7. 2013).

${ }^{237}$ HERRN, Transvestitismus 368.

238 Ebd.

${ }^{239} \mathrm{http}: / /$ www.verwaltungsgeschichte.de/aus_stpoelte n.html (abgerufen am 29. 7. 2013).

${ }^{240}$ http://www.verwaltungsgeschichte.de/aus_lilienfel d.html (abgerufen am 29. 7. 2013). 
Schlussendlich zeigt dieser Beitrag auf, dass durch eine verstärkte Einbeziehung des Archivmaterials zu behördlichen Vornamensänderungen und Personenstandskorrekturen neue Ergebnisse zu erzielen sind. Sie betreffen zwar nur diejenigen inter- und transsexuellen Personen, die den Weg einer juristischen Geschlechtsumwandlung beschritten, und beruhen auf durch die Notwendigkeiten des Verwaltungsverfahrens geprägten Narrativen, können aber dennoch der Rekonstruktion von Lebenswirklichkeiten dienen und Einblicke in Behördenpraktiken bieten.

\section{Korrespondenz:}

Dr. in Ilse Reiter-Zatloukal

Institut für Rechts- und Verfassungsgeschichte

Universität Wien

1010 Wien, Schottenbastei 10-16

ilse.reiter-zatloukal@univie.ac.at

\section{Literatur:}

Hans ABRAHAM, Der weibliche Transvestitismus (med. Diss., Univ. Berlin 1912).

Emanuel ADLER, Der Namen im deutschen und österreichischen Recht (Wien 1920).

ANONYMUS, Über die Behandlung der sog. Transvestiten, in: Deutsche Strafrechts-Zeitung 9 (1922) 171.

Wilhelm ARBESSER, Wilhelm LOEBELL (Hgg.), Das Verwaltungsstrafgesetz (= Manzsche Ausgabe der Österreichischen Gesetze 19, Wien 1933).

Ingrid ARIAS, Die Wiener Gerichtsmedizin im Nationalsozialismus (Wien 2009).

Christine BARD, Nicole PELlegrin (Hgg.), Femmes travesties: Un "mauvais" genre (= CLIO. Histoire, Femmes et Sociétés 10, Toulouse 1999).

Walter BARFUß, Verrechtlichung des Verwaltungsstrafverfahrens, in: Anwaltsblatt 60/Nr. 4 (1998) 218-225.

Wilfried BEIMROHR, Die Matriken (Personenstandsbücher) der Diözese Innsbruck und des Tiroler Anteils der Erzdiözese Salzburg (=Tiroler Geschichtsquellen 17, Innsbruck 1987).

Harry BENJAMIN, The Transsexual Phenomenon (New York 1966).
Harry BENJAMIN, Transvestitism and Transsexualism, in: International Journal of Sexology 7 (1953), 12-14.

Elisabeth BERGER, Erwerb und Änderung des Familiennamens (= Rechts- und Staatswissenschaftliche Reihe 29, Frankfurt am Main 2001).

Ernst BERGMANN, Erkenntnisgeist und Muttergeist. Eine Soziosophie der Geschlechter (Breslau 1933).

Iwan BLOCH, Beiträge zur Ätiologie der Psychopathia sexualis (Dresden 1902-1903)

Iwan BLOCH, Das Sexualleben unserer Zeit (Berlin 1907).

Vern L. Bullogh, Bonnie Bullough, Crossdressing, Sex and Gender (Philadelphia 1993).

David O. CAULDWELL, Psychopathia Transsexualis, in: Sexology 16 (1949) 274-280.

Council of Europe, Le transsexualisme en Europe. Commission internationale de l'état civil (CIEC) (Straßburg 2008).

Rudolf DEKKER, Lotte VAN DE POL, Frauen in Männerkleidern. Weibliche Transvestiten und ihre Geschichte (Berlin 1989).

Hans-Peter DIENES, Der weibliche Transvestitismus und Transsexualismus (Bonn 1973).

Alice DOMURAT Dreger, Hermaphrodites and the Medical Invention of Sex (Cambridge-London 1998).

Richard EKINS, Dave KING, The transgender phenomenon (London 2006).

Anne Fausto-Sterling, Sexing the Body. Gender Politics and the Construction of Sexuality (New York 2000).

Leslie FEINBERG, Gender Warriors. Making History from Joan of Arc to Dennis Rodman (Boston 1996).

Michel FOUCAULT, Das wahre Geschlecht, in: Herculine BARBIN, Michel FouCAUlt, Über Hermaphrodismus, hg. v. Wolfgang SCHÄFFNER, Joseph VOGL (Frankfurt am Main 1998) 7-18.

Marjorie GARBER, Vested interests. Cross-Dressing \& cultural anxiety (New York-London 1992).

Günter GRAU (Hg.), Homosexualität in der NS-Zeit. Dokumente einer Diskriminierung und Verfolgung (Frankfurt am Main 1993).

Franz GÜRTNER (Hg.), Das kommende deutsche Strafrecht. Besonderer Teil: Bericht über die Arbeit der amtlichen Strafrechtskommission (Berlin 1935).

Hanna HACKER, Die Ordnung der Frauen und Freundinnen. Zur Rekonstruktion homosexueller Handlungsmuster und ihrer institutionellen Kontrolle (Österreich, 1870-1938) (phil. Diss., Univ. Wien 1985). 
Hanna HACKER, Frauen und Freundinnen. Studien zur „weiblichen Homosexualität“ am Beispiel Österreich 1870-1938 (Weinheim-Basel 1987).

Hanna HACKER, Tödlich, humorvoll. Wien und die Wienerin in der lesbischen Literatur, in: Neda BEI, Wolfgang FORSTER, Hanna HACKER, Manfred LANG, Das lila Wien. Zur Ästhetik der Homosexualitäten (Wien 1986) 21-35.

Gudrun HAUER, Lesben und Nationalsozialismus: Blinde Flecken in der Faschismustheoriediskussion, in: Lambda-Nachrichten, Sondernummer Juni 2001, 46-52.

Hans HausteIn, Transvestitismus und Staat am Ende des 18. und im 19. Jahrhundert, in: Sexualwissenschaft und Sexualpolitik 15 (1928) 116-122.

Henry Havelock ElLIS, John EDDINGTON SYMONDS, Das konträre Geschlechtsgefühl (Leipzig 1896).

Friedrich HERBER, Gerichtsmedizin unterm Hakenkreuz (Leipzig 2002).

Rainer HERRN, Das Geschlecht ruht nicht im Körper, sondern in der Seele - Magnus Hirschfelds Strategien bei Hermaphroditengutachten, in: Neue Gesellschaft für Bildende Kunst (Hg.), 1-0-1 Intersex. Das Zwei-Geschlechter-System als Menschenrechtsverletzung (Berlin 2005) 55-71.

Rainer HERRN, Schnittmuster des Geschlechts, Transvestitismus und Transsexualität in der frühen Sexualwissenschaft (= Beiträge zur Sexualforschung 85, Gießen 2005).

Rainer HERRN, Transvestitismus in der NS-Zeit - Ein Forschungsdesiderat, in: Zeitschrift für Sexualforschung 26/Heft 4 (2013) 330-371.

Rainer HERRN, Ver-körperungen des anderen Geschlechts - Transvestitismus und Transsexualität historisch betrachtet, in: Aus Politik und Zeitgeschichte 20-21 (2012): Geschlechtsidentität, http://www.bpb.de/apuz/135444/ver-

koerperungen-des-anderen-geschlechtstransvestitismus-und-transsexualitaet-historischbetrachtet? $p=$ all (abgerufen am 29. 7. 2013).

Stefan HiRSCHAUER, Die soziale Konstruktion der Transsexualität. Über die Medizin und den Geschlechtswechsel (Frankfurt am Main 1993).

Magnus HIRSCHFELD, Ursachen und Wesen des Uranismus, in: Jahrbuch für sexuelle Zwischenstufen 5 (1903) 1-193.

Magnus HIRSCHFELD, Geschlechtsübergänge. Mischungen männlicher und weiblicher Geschlechtscharaktere (Sexuelle Zwischenstufen) (Leipzig 1905).

Magnus HIRSCHFELD, Die Transvestiten. Eine Untersuchung über den erotischen Vertreibungstrieb.
Mit umfangreichem casuistischen und historischen Material (Berlin 1910).

Magnus HIRSCHFELD, Geschlechts-Umwandlungen. Irrtümer in der Geschlechtsbestimmung (= Beiträge zur forensischen Medizin 1/Heft 2, Berlin 1912).

Magnus HiRSCHFELD, Schuldig geboren, in: Ludwig LEVY-LENZ (Hg.), Der Arzt im Hause (Wien 1927) $1-105$.

Magnus HIRSCHFELD, Sexualität und Kriminalität (Wien-Berlin-Leipzig-New York 1924)

Magnus HIRSCHFELD, Sexualpathologie. Ein Lehrbuch für Ärzte und Studierende, 2. Teil: Sexuelle Zwischenstufen. Das männliche Weib und der weibliche Mann (Bonn 1918).

Marion HULVERSCHEIDT, Rezension von: Rainer Herrn: Schnittmuster des Geschlechts. Transvestitismus und Transsexualität in der frühen Sexualwissenschaft (Gießen 2005), in: sehepunkte 6/Nr. 3 (2006), http://www.sehepunkte.de/2006/03/9795.html (abgerufen am 29. 7. 2013).

Burkhard JELLONEK, Homosexuelle unter dem Hakenkreuz. Die Verfolgung von Homosexuellen im Dritten Reich (Paderborn 1990).

Burkhard JELLONEK, Staatspolizeiliche Fahndungsund Ermittlungsmethoden gegen Homosexuelle. Regionale Differenzen und Gemeinsamkeiten, in: Gerhard PAul,Klaus-Michael MallmanN (Hgg.), Gestapo. Mythos und Realität (Darmstadt 1995) 343-356.

Louise J. KaPLAN, Weibliche Perversionen. Von befleckter Unschuld und verweigerter Unterwerfung (Hamburg 1991).

Jonathan KATZ, Passing Women: 1782-1920, in: DeRS. (Hg.), Gay American History (New York 1997) 317-322.

Rudolf KLARE, Homosexualität und Strafrecht (Hamburg 1937).

Ulrich KLARE, Zum Problem der weiblichen Sexualität, in: Deutsche Justiz (Wiener Ausgabe) 2 (1939) 19-22.

Ulrike KLÖPPEL, XXOXY ungelöst. Hermaphroditismus, Sex und Gender in der deutschen Medizin. Eine historische Studie zur Intersexualität (Bielefeld 2010).

Richard von KRAFFT-EBBING, Psychopathia Sexualis mit besonderer Berücksichtigung der conträren Sexualempfindung. Eine medicinisch-gerichtliche Studie für Ärzte und Juristen (Stuttgart 111910; ${ }^{14} 1912$, ND hg. von Alfred FuCHS, München 1997).

Wilhelm LAHM, Ovarium, Uterus, Scheide, Klitoris, Plazenta und Brustdrüse als innersekretorische Drüsen vom Standpunkte der Embryologie und Morphologie, in: Max HiRsch (Hg.), Handbuch 
der inneren Sekretion. Eine umfassende Darstellung der Anatomie, Physiologie und Pathologie der endokrinen Drüsen, Bd. 1 (Berlin 1929) 123196.

Thomas LAQUeUR, Auf den Leib geschrieben. Die Inszenierung der Geschlechter von der Antike bis Freud (Frankfurt am Main-New York 1992).

Kerstin LOSERT, Kleider machen Männer. Mittelalterliche Geschlechterkonstruktion und die Legende der Hildegard von Schönau, in: invertito. Jahrbuch für die Geschichte der Homosexualitäten 3 (2001) 68-93.

R. Valerie LUCAS, Hic Mulier. The Female Transvestite in Early Modern England, in: Renaissance and Reformation 24/1 (1988) 65-84.

Stefan Maiwald, Gerd Mischler, Sexualität unter dem Hakenkreuz. Manipulation und Vernichtung der Intimsphäre im NS-Staat (Hamburg-Wien 1999).

Geerte MAK, „Passing Women“ im Sprechzimmer von Magnus Hirschfeld. Warum der Begriff „Transvestit nicht für Frauen in Männerkleidern eingeführt wurde", in: Österreichische Zeitschrift für Geschichtswissenschaft 9/3: Homosexualitäten (1998) 384-399.

Geerte MAK, Hirschfeld und Transvestiten. Warum es nie etwas geworden ist zwischen Frauen in Männerkleidung und der Sexualwissenschaft, in: Manfred HERZER (Hg.), 100 Jahre Schwulenbewegung. Dokumentation einer Vortragsreihe in der Akademie der Künste (Berlin 1998) 157-169.

Geertje MAK, Menneljke vrouwen. Over grenzen van sekse in de negentiende eeuw (AmsterdamMeppel 1997)

Franz MAßFELLNER, Die Führung der Personenstandsbücher in Musterbeispielen. Handbuch für die deutschen Standesbeamten und ihre Aufsichtsbehörden (Berlin 1939).

Sabine MeHLManN, Unzuverlässige Körper. Zur Diskursgeschichte des Konzepts der geschlechtlichen Identität (Königstein/Taunus 2007).

Albert MolL, Handbuch der Sexualwissenschaften (Leipzig 21921).

Albert MÜLLER, Christian FLECK, „Unzucht wider die Natur“. Gerichtliche Verfolgung der „Unzucht mit Personen gleichen Geschlechts" in Österreich von den 1930er bis zu den 1950er Jahren, in: Österreichische Zeitschrift für Geschichtswissenschaften 9 (1998) 400-422.

Alois NiEDERSTÄTTER, Die kirchliche Matrikenführung bis 1939, in: Ulrich NACHBAUR, Alois NIEDERSTÄTTER (Hgg.), 200 Jahre Gemeindeorganisation in Vorarlberg (Bregenz 2009) 185-192.
Walther NiEMANN, Salomonisches Urteil, in: Jahrbuch für sexuelle Zwischenstufen mit besonderer Berücksichtigung der Homosexualität, 20/1 und 2 (1920) 145-146.

Günther NoÉ, „Amazonen“ in der österreichischen Geschichte, in: Österreich in Geschichte und Literatur 30 (1986) 350-361.

Hannelore PALKOW, André MARCHAND (Hgg.), Liebeslexikon von A-Z. Ein Aufklärungsbuch und Ratgeber für alle Fragen der Liebe (Wien-BerlinLeipzig 1932).

Wilhelm POLZER, Sexuellperverse. Populärwissenschaftliche Darstellung aller geschlechtlichen Perversionen und Verwandtes (Leipzig 1930).

Heribert PRANTL, Das gefühlte Geschlecht, 28.11. 2011, http://www.sueddeutsche.de/politik/verfassungsg ericht-kippt-transsexuellengesetz-das-gefuehltegeschlecht-1.1052344 (abgerufen am 29. 7. 2013).

Ilse Reiter-Zatloukal, Die ,Entschleierung' der „blutmäßigen Abstammung“. Das NS-Namensrecht und seine Implementierung in Österreich, in: Verena Halbwachs, Ilse ReIter-Zatloukal, Stefan SCHIMA (Hgg.), Die Kultur der Namensgebung (Wien 2014) (iE).

Anette RunTE, Biographische Operationen. Diskurse der Transsexualität (München 1996).

Heike SCHADER, Virile, Vamps und wilde Veilchen. Sexualität, Begehren und Erotik in den Zeitschriften homosexueller Frauen im Berlin der 1920er Jahre (Königstein/Taunus 2004).

Wolfgang SCHÄFFNER, Transformationen. Schreber und die Geschlechterpolitik um 1900, in: Elfi BETTINGER, Julia FunK (Hgg.), Maskeraden. Geschlechterdifferenz in der literarischen Inszenierung (= Geschlechterdifferenz \& Literatur 3, Berlin 1995) 273-291.

Christa SCHIKORRA, Kontinuitäten der Ausgrenzung. "Asoziale" Häftlinge im Frauen-Konzentrationslager Ravensbrück (= Dokumente - Texte - Materialien 41, Berlin 2011).

Kathrin SCHMERSAHL, Medizin und Geschichte - Zur Konstruktion der Kategorie Geschlecht im medizinischen Diskurs des 19. Jahrhunderts (Opladen 1998).

Franz von SCHMIDT, Nachtseiten der Liebe. Von Verwirrungen des Geschlechtslebens. Aus den Akten der Kriminalpolizei (Zürich-Stuttgart-Wien 1960).

Claudia SCHOPPMANN, Nationalsozialismus und Forschung zur weiblichen Homosexualität, in: Rüdiger LautManN (Hg.), Homosexualität. Handbuch der Theorie- und Forschungsgeschichte (Frankfurt am Main 1993) 215-225. 
Claudia ScHOPPMANN, Nationalsozialistische Sexualpolitik und weibliche Homosexualität (Pfaffenweiler 1991).

Claudia SchOPpMANN, Verbote Verhältnisse. Frauenliebe 1938-1945 (Berlin 1999).

Judith SCHWARZ, Researching Lesbian History, in: Sinister Wisdom Nr. 5 (1978) 55-59.

Claudia SCHOPPMANN, Zeit der Maskierung. Lebensgeschichten lesbischer Frauen im "Dritten Reich“ (Berlin 1993).

Josef SEIDL, Der österreichische Standesbeamte - gestern und heute, in: Ulrich NACHBAUR, Alois NIEDERSTÄTTER (Hgg.), 200 Jahre Gemeindeorganisation in Vorarlberg (Bregenz 2009) 193-196.

Myriam SPÖRRI, N. O. Body, Magnus Hirschfeld und die Diagnose des Geschlechts: Hermaphrodismus um 1900, in: L'Homme. Zeitschrift für Feministische Geschichtswissenschaft 14/2 (2003) 244-261.

Angela STEIDELE, In Männerkleidern. Das verwegene Leben der Catharina Margaretha Linck alias Anastasius Lagrantinus Rosenstengel, hingerichtet 1721. Biographie und Dokumentation (Köln-W eimar-Wien 2004).

Sylvie STEINBERG, La confusion des sexes. La travestissement de la Renaissance à la Révolution (Paris 2001).

Andrea Stoll, Verena WodTKe-Werner (Hgg.), Sakkorausch und Rollentausch. Männliche Leitbilder als Freiheitsentwürfe von Frauen (Dortmund 1997).

Susan STRYKER, Transgender History (Berkeley 2008).

Walter TETZLAFF, Homosexualität und Jugend, in: Der HJ-Richter (1942) 1-8.

Gisela URBAN, Zur Wohnungsfrage der berufstätigen alleinstehenden Frau, in: Österreicherin, Nr. 8 vom 1. 10. 1928, 4f.

Hermann Ferdinand Voss, Ein Beitrag zum Problem des Transvestitismus (Marburg 1938).

Andreas WACKE, Vom Hermaphroditen zum Transsexuellen. Zur Stellung von Zwittern in der Rechtsgeschichte, in: Heinz EYRICH, Walter ODERSKY, Franz Jürgen SÄCKER (Hg.), Festschrift für Kurt Rebmann zum 65. Geburtstag (München 1989) 861-903.

Patrick Wagner, Hitlers Kriminalisten. Die deutsche Kriminalpolizei und der Nationalsozialismus zwischen 1920 und 1960 (München 2002).
Patrick WAGNER, Volksgemeinschaft ohne Verbrecher. Konzeptionen und Praxis der Kriminalpolizei in der Zeit der Weimarer Republik und des Nationalsozialismus (= Hamburger Beiträge zur Sozialund Zeitgeschichte 34, Hamburg 1996).

Michael WAGNER-KERN, Staat und Namensänderung. Die öffentlichrechtliche Namensänderung in Deutschland im 19. und 20. Jahrhundert (= Beiträge zur Rechtsgeschichte des 20. Jahrhunderts 35, Tübingen 2002).

Niko WAHL, Verfolgung und Vermögensentzug Homosexueller auf dem Gebiet der Republik Österreich während der NS-Zeit. Bemühungen um Restitution, Entschädigung und Pensionen in der Zweiten Republik (= Veröffentlichungen der Österreichischen Historikerkommission. Vermögensentzug während der NS-Zeit sowie Rückstellungen und Entschädigungen seit 1945 in Österreich 25, Wien-München 2004).

Franz WeIsS, Die Geheime Staatspolizei Staatspolizeileitstelle Wien 1938-1945 (phil. Diss., Univ. Wien).

Ulrike WETZ, Geschichte der Wiener Polizeidirektion vom Jahre 1945 bis zum Jahre 1955 (phil. Diss., Univ. Wien 1971).

Eugen WILHELM, Die rechtliche Stellung der (körperlichen) Zwitter de lege lata und de lege ferenda. (= Juristisch-psychiatrische Grenzfragen VII/1, Halle 1909).

Eugen WilHelm, Die Transvestiten und das Recht, in: Sexualprobleme 10 (1914) 393-408, 495-503.

Eugen WILHELM, I. Geschlechtsbestimmung der (körperlichen Zwitter). II. Zwitter und Standesregister, in: Vierteljahresschrift für gerichtliche Medizin und öffentliches Sanitätswesen 48 (1914) 260-280.

Raimund WOLFERT, Skandinavien: Grundsteinlegung und Konsolidierung, in: Andreas STERNWEILER, Hans Gerhard HANNESEN (Hgg.), Goodbye to Berlin? 100 Jahre Schwulenbewegung. Eine Ausstellung des Schwulen Museums und der Akademie der Künste 17.5. bis 17.8. 1997 (Berlin 1997) 233-137.

Stefanie WOLTER, Lebenssituationen und Repressionen von Lesben, Schwulen, Bisexuellen, Transund Intersexuellen im Nationalsozialismus. Ein Workshopbericht, http://www.ifz-muenchen.de/fileadmin/images/ Neuigkeiten/2013/Workshopbericht_Homosexu alit\%C3\%A4t $\% 20 \mathrm{im} \% 20 \mathrm{NS} \% 20$ ausf $\%$ C3\% BChrlich.pdf (abgerufen am 29. 7. 2013). 